\title{
Bias correction of temperature and precipitation over China for RCM simulations using the QM and QDM methods
}

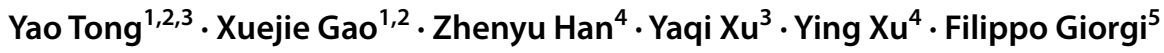

Received: 4 March 2020 / Accepted: 26 August 2020 / Published online: 8 September 2020

(c) The Author(s) 2020

\begin{abstract}
Two different bias correction methods, the quantile mapping (QM) and quantile delta mapping (QDM), are applied to simulated daily temperature and precipitation over China from a set of 21 st century regional climate model (the ICTP RegCM4) projections. The RegCM4 is driven by five different general circulation models (GCMs) under the representative concentration pathway RCP4.5 at a grid spacing of $25 \mathrm{~km}$ using the CORDEX East Asia domain. The focus is on mean temperature and precipitation in December-January-February (DJF) and June-July-August (JJA). The impacts of the two methods on the present day biases and future change signals are investigated. Results show that both the QM and QDM methods are effective in removing the systematic model biases during the validation period. For the future changes, the QDM preserves the temperature change signals well, in both magnitude and spatial distribution, while the QM artificially modifies the change signal by decreasing the warming and modifying the patterns of change. For precipitation, both methods preserve the change signals well but they produce greater magnitude of the projected increase, especially the QDM. We also show that the effects of bias correction are variable- and season-dependent. Our results show that different bias correction methods can affect in different way the simulated change signals, and therefore care has to be taken in carrying out the bias correction process.
\end{abstract}

Keywords Regional climate model $\cdot$ Bias correction $\cdot$ Quantile delta mapping $\cdot$ China

\section{Introduction}

While general circulation models (GCMs) produce important climate change information on the global scale, they are still characterized by an excessively coarse resolution to provide information for impact studies. Regional climate models (RCMs) with higher horizontal resolution have been widely used in recent decades (Giorgi 2019) to downscale GCM simulations and provide fine scale regional climate information. They can be especially useful for the East Asia

Xuejie Gao

gaoxuejie@mail.iap.ac.cn

1 Climate Change Research Center, Institute of Atmospheric Physics, Chinese Academy of Sciences, Beijing, China

2 University of Chinese Academy of Sciences, Beijing, China

3 Yingkou Meteorological Bureau, Yingkou, China

4 National Climate Center, China Meteorological Administration, Beijing, China

5 The Abdus Salam International Center for Theoretical Physics, Trieste, Italy region, whose climate is dominated by the East Asia monsoon and is characterized by a large diversity both in space and time.

As reported in previous studies, high resolution RCM simulations show better performance in reproducing present day climate over China, and particularly the development of the East Asia monsoon (Gao et al. 2006). In addition, RCMs tend to project different change pattern compared to the driving GCMs due to a more realistic topographic and land use forcings (e.g., Gao et al. 2006, 2012; Zou and Zhou 2013; Yu et al. 2015; Gao and Giorgi 2017; Huang et al. 2018).

As well known, systematic biases of climate model simulations relative to observations widely exist due to various reasons. It can be very difficult and sometimes even not possible to use model outputs directly in impact assessment studies, e.g., as forcings for hydrological and agricultural models. Thus, bias correction has been widely used to postprocess the climate model output prior to application for impact studies (Wood et al. 2004; Boé et al. 2007; Ashfaq et al. 2010; Piani et al. 2010; Yang et al. 2010; Hagemann et al. 2011; Teutschbein and Seibert 2012; Eden et al. 2012). 
A number of bias-correction methods have been developed, although those employing quantile mapping (QM) are the most commonly used (Eden et al. 2012; Maraun 2013; Mehrotra and Sharma 2016; Ngai et al. 2017; Han et al. 2018; Yang et al. 2018). In the QM method a transfer function (TF) depending on the quantile distribution is first established by matching daily values in present day simulations with observations during a reference period. This is then applied to other periods of the model simulations, e.g., future time slices. Typically, a validation period is selected and the bias corrected variables are compared against observations to evaluate its performance. As reported by previous studies, the QM method effectively removes model biases, not only for the mean and interannual variability, but also for extreme events (e.g., Wood 2002; Wood et al. 2004; Boé et al. 2007; Piani et al. 2009; Ashfaq et al. 2010; Piani et al. 2010; Teutschbein and Seibert 2012; Gudmundsson et al. 2012; Tong et al. 2017).

In general, the QM method assumes that the cumulative distribution function (CDF) for a variable in the simulation and observation time series remains un-changed in the future period. However, this distribution has been found to change in future projections (IPCC 2013), and therefore the QM method may artificially distort the climate change signals and corrupt future model-projected trends (Ahmed et al. 2013; Bürger et al. 2013). This calls for a method that can effectively preserve relative or absolute changes in simulated quantiles (Haerter et al 2010; Li et al. 2010; Willems and Vrac 2011; Bürger et al. 2012; Bürger et al. 2013; Hempel et al. 2013; Cannon et al. 2015; Pierce et al. 2015).

One QM method is, the non-parametric QM using robust empirical quantiles (RQUANT) (Gudmundsson et al. 2012), which has been used to bias correct daily precipitation and temperature over China in a RCM simulation driven by reanalysis data over China (Tong et al. 2017; Han et al. 2018). Therefore, here we apply this non-parametric QM method to a series of 21st century climate projections over an East Asia domain by the same RCM driven by different GCMs.

We also test a different bias-correction method, named the quantile delta mapping (QDM) (Cannon et al. 2015). The QDM is based on the quantile delta change and detrended quantile mapping method as described by Cannon et al. (2015), which is close to the equidistant cumulative distribution function (EDCDF) method as in Li et al. (2010) and the quantile delta change as in Olsson et al. (2009) (see Sect. 2.2 below for more detail).

The main purpose of this paper is to investigate how these two bias-correction methods modulate the climate change signal over China and to intercompare the results from the methods in order to assess which is more appropriate to use in post-processing of climate variables for application to impact studies. We stress that intercomparative analyses of different bias-correction methods applied to high resolution models for the China territory to our knowledge are not available in the literature, and therefore our study can be especially useful in increasing understanding of this technique, which is increasingly being used in a wide range of impact applications. In addition, the use of an ensemble of simulations for post-processing increases the robustness of our results compared to previous RCM-based studies.

The methods and experiments are described in the next section, while results are discussed in Sect. 3, both for the present day reference period and the future climate change signal.

\section{Model, data and methods}

\subsection{Model and data}

The model employed here is the Abdus Salam International Center for Theoretical Physics (ICTP) Regional Climate Model version 4 (RegCM4) (Giorgi et al. 2012). The Coordinated Regional Climate Downscaling Experiment (CORDEX) Phase II East Asia domain is used in the simulations (Giorgi et al. 2009), which covers the whole of China and its surrounding East Asia areas (Fig. 1). The model is run at $25 \mathrm{~km}$ grid spacing with 18 vertical sigma layers and a model top at $10 \mathrm{hPa}$. The configuration of the model follows Gao et al. $(2016,2017)$ with the land cover data over China updated to represent the realistic vegetation cover as in Han et al. (2015). The initial and time evolving lateral boundary conditions needed to drive RegCM4 are derived from 5 GCMs from the Phase 5 of the Coupled Model Intercomparison Project (CMIP5, Taylor et al. 2012): CSIRO-Mk3-6-0, EC-EARTH, HadGEM2-ES, MPI-ESM-MR and NorESM1M (Rotstayn et al. 2010; Hazeleger et al. 2010; Collins et al. 2011; Stevens et al. 2012; Jungclaus et al. 2013; Bentsen et al. 2012; Iversen et al. 2013, respectively). These GCMs were selected due to their higher resolution in the CMIP5 ensemble, the data availability as well as their relatively good performance over the region (Jiang et al. 2016).

The RegCM4 simulations cover the period 1968-2005 for the present day, with observed greenhouse gas concentrations, and 2006-2099 for the future period (Gao et al. 2018) with greenhouse gas concentrations following the representative concentration pathway RCP4.5 (Moss et al. 2010). Following the GCMs, the five RegCM4 simulations conducted are referred to as $\mathrm{CdR}, \mathrm{EdR}, \mathrm{HdR}, \mathrm{MdR}$, and $\mathrm{NdR}$, respectively.

The gridded observational dataset CN05.1 (Wu and Gao 2013) at a resolution of $0.25^{\circ} \times 0.25^{\circ}$ (latitude $\times$ longitude) is used to validate and bias correct the simulations. $\mathrm{CN} 05.1$ is based on the interpolation from over 2400 observing stations in China as an augmentation of CN05 (Xu et al. 2009). 
Fig. 1 Model domain (gray in a), topography (shaded, unit: $\mathrm{m})$ and the 10 river basins over China (b). 1. Songhuajiang River Basin (SRB); 2. Liaohe Basin (LRB); 3. Haihe Basin (HaiRB); 4. Yellow River Basin (YLB); 5. Huai River Basin (HRB); 6. Yangtze River Basin (YRB); 7. Zhujiang River Basin (ZRB); 8. Southeast Rivers Basin (SERB); 9 Southwest Rivers Basin (SWRB); 10. Interior rivers in the Northwest Basin (NWRB)

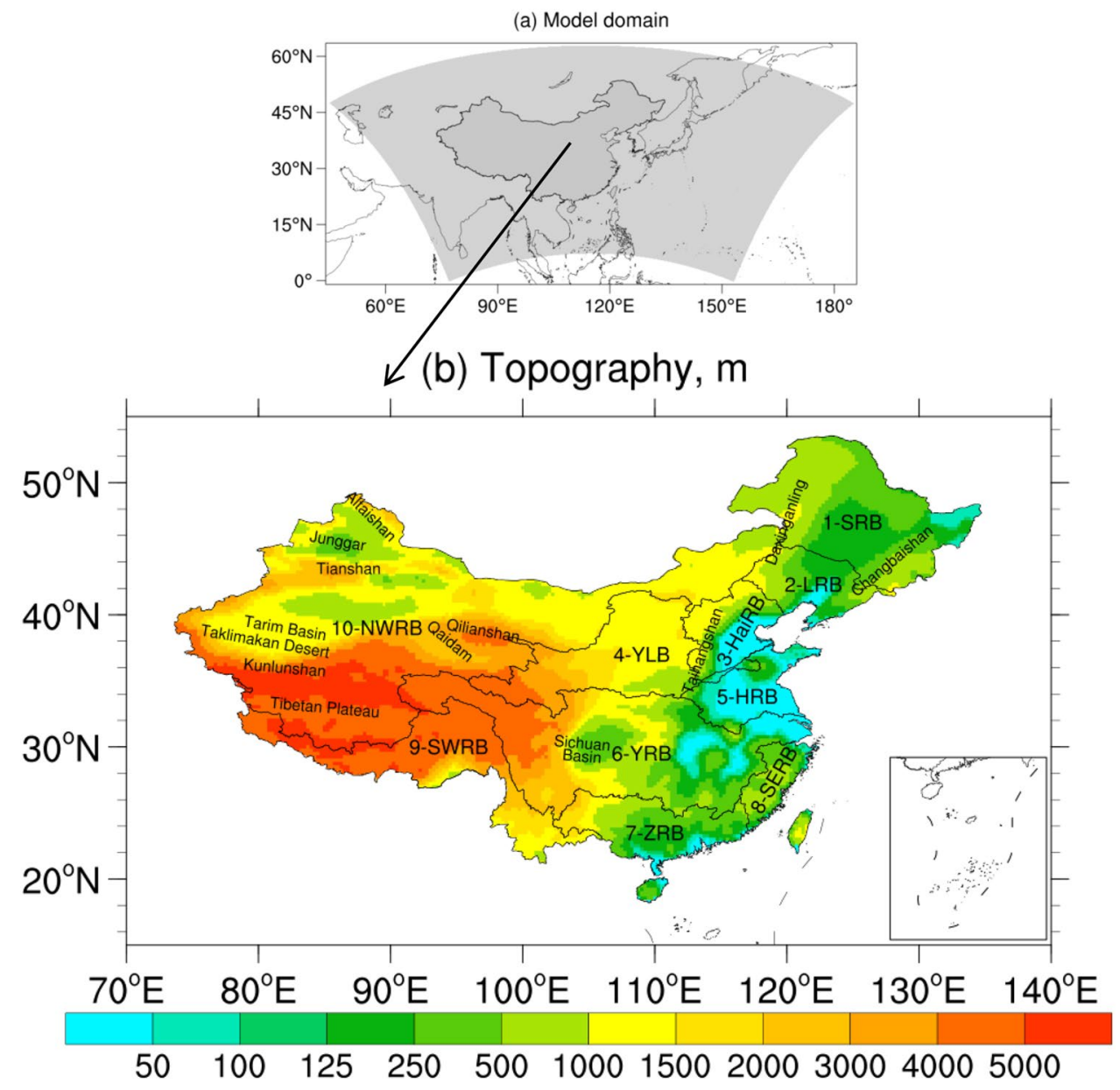

The model outputs are linearly interpolated to the same grid as in CN05.1.

The bias adjustment calibration period covers 1981-2000 and the period 2001-2015 is used to validate the performance of the bias correction methods for present day climate conditions. Projected changes by the end of the 21 st century for the period 2079-2098 with respect to the reference period 1986-2005 are then analyzed, with comparisons of the QM and QDM results against the original uncorrected change signal.

The bias correction is applied to each simulation separately, but here we focus on the ensemble mean temperature and precipitation in DJF (December-January-February) and JJA (June-July-August) to increase robustness of the results. In addition, a correction to account for dry-day frequency is applied in both bias-correction methods, because climate models tend to simulate light rain days instead of dry days which cannot be corrected directly by using the TF (Teutschbein and Seibert 2012; Gudmundsson et al. 2012; Cannon et al. 2015). The TFs are constructed and applied for each season separately.
Ten major river basins within the Chinese territory (MWRC 1981; Fig. 1) are employed as sub-regions in view of the future use of the data in hydrological studies (e.g., Liu et al. 2016; Su et al. 2017). The basins are Songhuajiang River Basin (SRB), Liaohe Basin (LRB), Haihe Basin (HaiRB), Yellow River Basin (YLB), Huai River Basin (HRB), Yangtze River Basin (YRB), Zhujiang River Basin (ZRB), Southeast Rivers Basin (SERB), Southwest Rivers Basin (SWRB), and interior rivers in the Northwest Basin (NWRB).

\subsection{Methods}

\subsubsection{Non-parametric quantile mapping using robust empirical quantiles}

Given a certain variable $\mathrm{x}$, the QM method is designed to minimize the difference between the empirical cumulative distribution functions (CDFs) of the original model output data and that of the observations during a calibration period (1981-2000) using Eq. (1). Equation (2) is then applied to 
(a) Observation in DJF, ${ }^{\circ} \mathrm{C}$

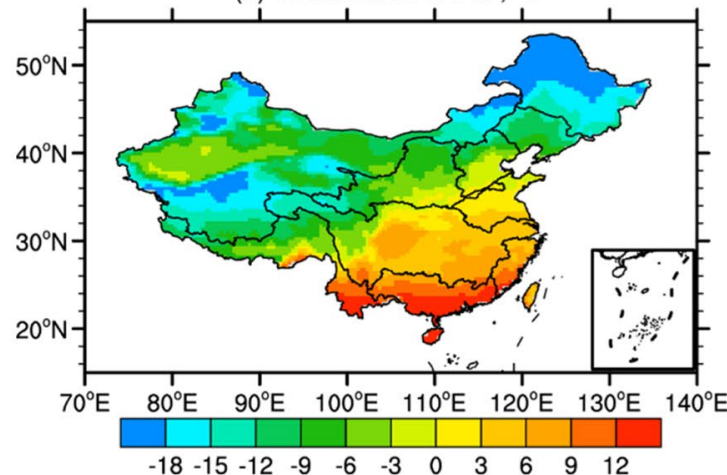

(c) Diff. of Tm. in DJF, ensR-CN05.1, ${ }^{\circ} \mathrm{C}$

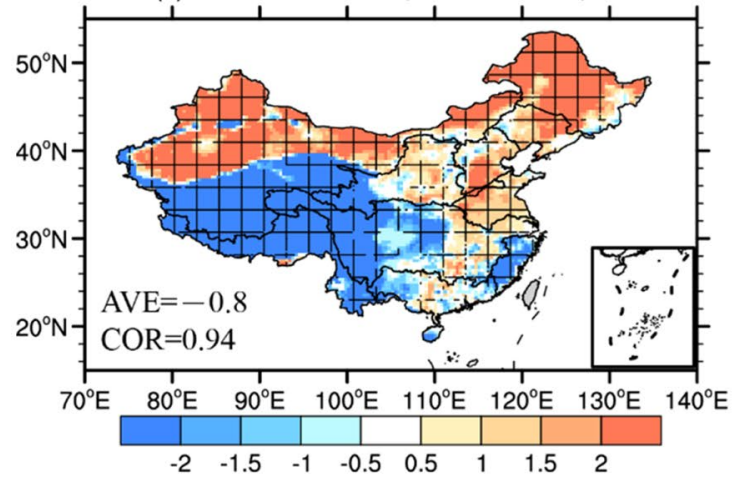

(e) Diff. of Tm. in DJF, ensR_QM-CN05.1, ${ }^{\circ} \mathrm{C}$

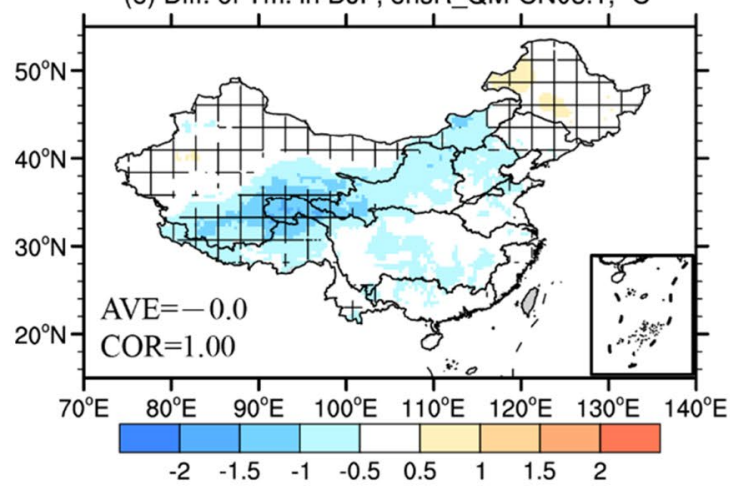

(g) Diff. of Tm. in DJF, ensR_QDM-CN05.1, ${ }^{\circ} \mathrm{C}$

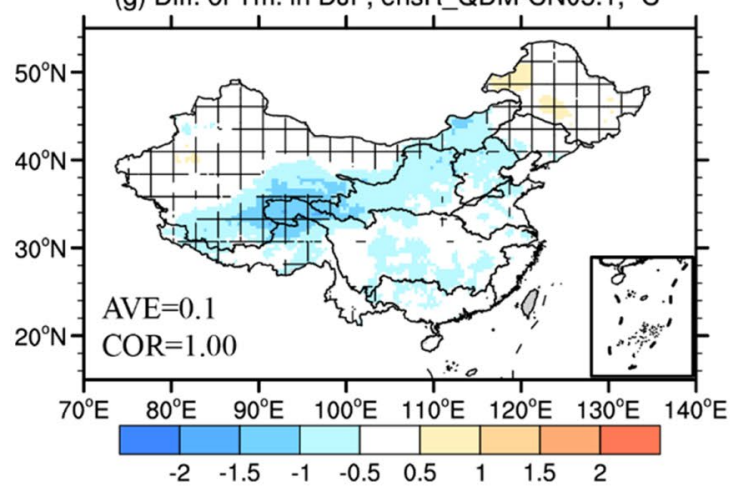

(b) Observation in JJA, ${ }^{\circ} \mathrm{C}$

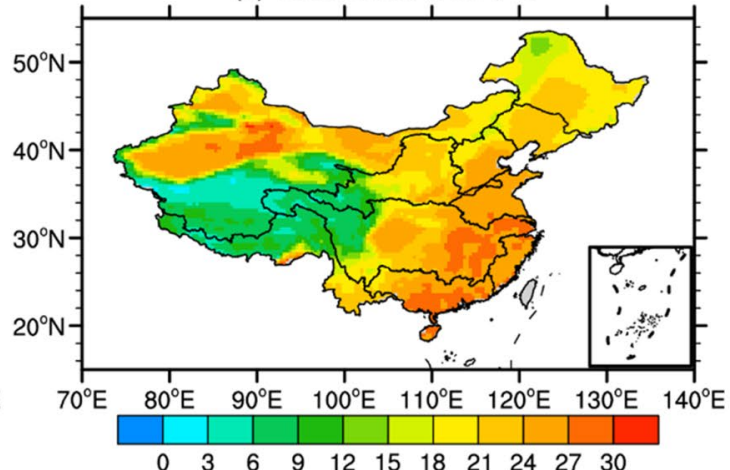

(d) Diff. of Tm. in JJA, ensR-CN05. $1,{ }^{\circ} \mathrm{C}$

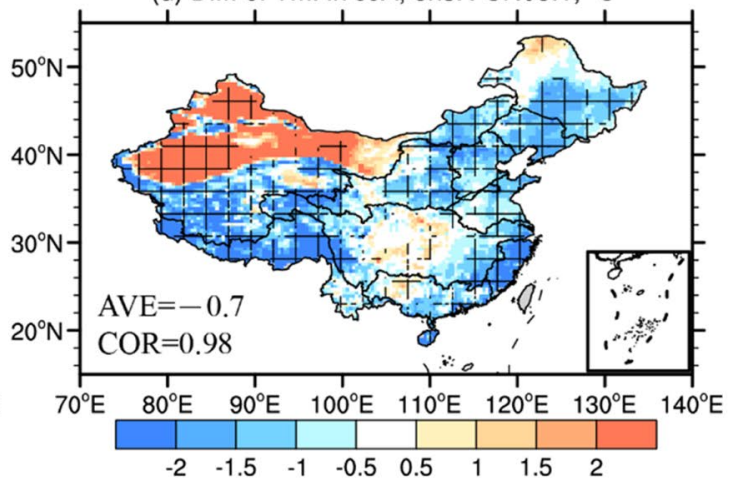

(f) Diff. of Tm. in JJA, ensR_QM-CN05.1, ${ }^{\circ} \mathrm{C}$

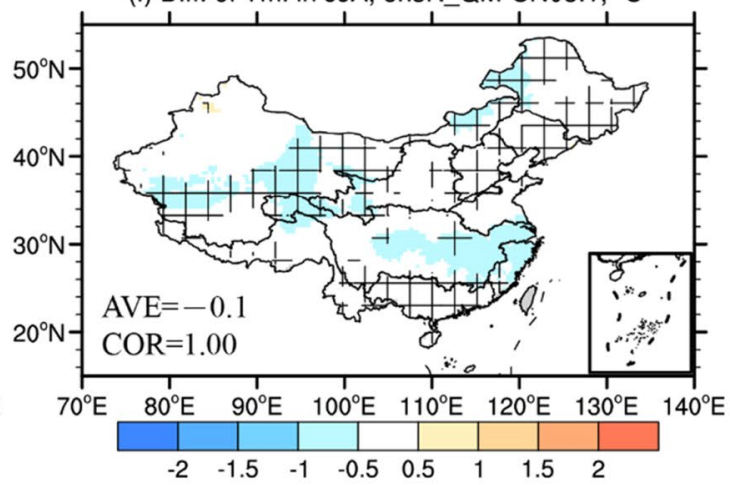

(h) Diff. of Tm. in JJA, ensR_QDM-CN05.1, ${ }^{\circ} \mathrm{C}$

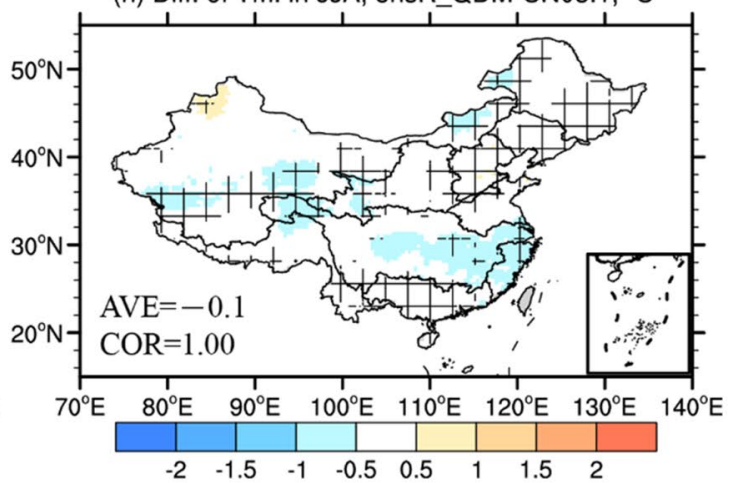


4Fig. 2 Mean temperature from observation and biases during 20012015 over China (units: ${ }^{\circ} \mathrm{C}$ ): $\mathbf{a}$ observation in DJF; $\mathbf{b}$ observation in JJA; $\mathbf{c}$ biases in DJF; $\mathbf{d}$ biases in JJA; $\mathbf{e}$ biases of ensR_QM in DJF; $\mathbf{f}$ biases of ensR_QM in JJA; $\mathbf{g}$ biases of ensR_QDM in DJF; $\mathbf{h}$ biases of ensR_QDM in JJA. Cross area in panels indicates that all simulations simulated the negative/positive bias. Regional mean over the whole of China and the CORs with observation for $\mathbf{c}$ to $\mathbf{h}$ are provided in the lower left corner of the panels

the rest of the 21 st century time series to correct future values of $\mathrm{x}$ :

$F_{m, c}\left(x_{m, c}\right)=F_{o, c}\left(x_{o, c}\right)$,

$x_{b c}=F_{o, c}^{-1}\left[F_{m, p}\left(x_{m, p}\right)\right]$,

where $x_{b c}$ is the bias corrected result; model data is denoted by the subscript $m$, where $x_{m, c}, F_{m, c}$ and $x_{m, p}, F_{m, p}$ are the variable's simulated values during the calibration period (denoted by the subscript $c$ ) and projected period (denoted by the subscript $p$ ), along with their corresponding empirical CDFs $(F)$, respectively; $x_{o, c}$ and $F_{o, c}^{-1}$ are the observed data (denoted by the subscript $o$ ), and the corresponding inverse empirical CDFs.

Previous studies have shown that using nonparametric transformations to establish transfer functions has the advantage of not requiring specific assumptions on the distribution of the original data (Boé et al. 2007; Gudmundsson et al. 2012; Tong et al. 2017). The RQUANT method is a non-parametric quantile mapping using robust empirical quantiles. It estimates the values of the quantile-quantile relation of observed and model time series for regularly spaced quantiles using local linear least square regression, and performs quantile mapping by interpolation of the empirical quantiles.

The calculation is based on the $\mathrm{R}$ language packages qmap, with further information available in Gudmundsson (2012) and https://cran.r-project.org/web/packages/qmap/index.html.

\subsubsection{Quantile delta mapping}

Quantile delta mapping (QDM) preserves the changes in quantiles and is equivalent to the equidistant and equiratio forms of the QM as described by Cannon et al. (2015). The model projection is detrended by quantiles firstly, and the simulated value is bias corrected by $\mathrm{QM}$ with the transfer function constructed in the calibration period. Then the projected absolute (for temperature) or relative (for precipitation) changes in quantiles are added or multiplied to the bias corrected model outputs to obtain the final results.

To be more specific, for a climate variable $x$, we first calculate the nonexceedance probability associated with the value at time $t$ :
$\varepsilon(\mathrm{t})=F_{m, p}^{(t)}\left[x_{m, p}(t)\right]$,

where $x_{m, p}(t)$ is a modeled value at time $t$ within the projection period, denoted by the subscript $p . \varepsilon(\mathrm{t})$ has a range from 0 to $1 . F_{m, p}^{(t)}$ is the time-dependent CDF of the model projected series $x_{m, p}$, which is estimated from the empirical CDF over a time window around $t$, using 30 -year moving windows.

For precipitation, the relative change in quantiles between the calibration periods and project time $t$ can be written as:

$\Delta(\mathrm{t})=\frac{F_{m, p}^{(t)-1}[\varepsilon(\mathrm{t})]}{F_{m, c}^{-1}[\varepsilon(\mathrm{t})]}=\frac{x_{m, p}(t)}{F_{m, c}^{-1}\left\{F_{m, p}^{(t)}\left[x_{m, p}(t)\right]\right\}}$,

while for temperature, the absolute change in quantiles between the calibration periods and future periods is written as:

$\Delta(\mathrm{t})=F_{m, p}^{(t)-1}[\varepsilon(\mathrm{t})]-F_{m, c}^{-1}[\varepsilon(\mathrm{t})]=x_{m, p}(t)-F_{m, c}^{-1}\left\{F_{m, p}^{(t)}\left[x_{m, p}(t)\right]\right\}$,

where $F_{m, c}^{-1}$ is the inverse CDF of the simulations in the calibration periods. It is also possible to bias correct the simulated $\varepsilon$ quantile at model-projected time $t$ over the calibration periods from observed values, as follows:

$\widehat{x}(\mathrm{t})=F_{o, c}^{-1}[\varepsilon(\mathrm{t})]$,

where $F_{o, c}^{-1}$ is the inverse CDF estimated from observed values $x_{\mathrm{o}, \mathrm{c}}$ at the calibration periods.

Finally, the bias-correction results in the future period at time $t$ equals this bias correction $\hat{x}$ multiplied by the relative change $\Delta(\mathrm{t})$ for precipitation (Eq. 7) and added to the absolute change in quantiles $\Delta(\mathrm{t})$ for temperature (Eq. 8), as follows:

$x_{b c}(\mathrm{t})=\hat{x}(\mathrm{t}) \Delta(\mathrm{t})$

$x_{b c}(\mathrm{t})=\hat{x}(\mathrm{t})+\Delta(\mathrm{t})$,

The calculation is based on the $\mathrm{R}$ language packages 'MBC', https://cran.r-project.org/web/packages/MBC/index .html.

\section{Validation}

\subsection{Temperature}

Figure 2 presents the mean observed temperature, the ensemble mean (ensR) model bias (simulation minus 
observations), and the ensembles mean biases of the biascorrected model simulation using the QM and QDM (ensR QM and ens_QDM) methods for the validation period in DJF and JJA over China. The observed temperature in DJF shows a pronounced latitudinal gradient (Fig. 2a), while high temperatures prevail over eastern China in JJA (Fig. 2b), and a strong topographical signal is found over western China.

The temperature biases of ensR in DJF show a general warm bias in high latitudes during the cold season (Fig. 2c), consistent to previous model simulations driven by re-analysis fields (Gao et al. 2017) as well as most GCMs (e.g., Jiang et al. 2016). Meanwhile, a dominant cold bias over the Tibetan Plateau is found. In JJA (Fig. 2d), the model shows a warm bias over the desert areas in the Northwest, while a cold bias prevails elsewhere except over the Sichuan Basin. The simulations show bias patterns in agreement among the individual realizations, with major biases consistent across models indicated by hatched areas in the figures. This result is consistent with $\mathrm{Wu}$ and Gao (2020) when analyzing 4 simulations of the series during the period of 1986-2005.

The analysis of different sub-regions indicates that the temperature biases of ensR in DJF show the largest warm bias over the SRB $\left(2.6^{\circ} \mathrm{C}\right)$ in Northeast China (Table 1), while the maximum cold bias is found in SWRB $\left(-5.3^{\circ} \mathrm{C}\right)$ followed by SERB $\left(-2.3^{\circ} \mathrm{C}\right)$. In NWRB, the large warm bias in the Northwest counterbalances the cold bias in the Tibetan Plateau leading to a relatively small mean value of $-0.3{ }^{\circ} \mathrm{C}$. In JJA, the biases are all negative over the different basins, with maxima of $-1.9^{\circ} \mathrm{C}$ and $-1.8{ }^{\circ} \mathrm{C}$ for SWRB

Table 1 Biases of mean temperature (units: ${ }^{\circ} \mathrm{C}$ ) and precipitation (\%) for ensR and the spatial correlation coefficients (CORs) between ensR and observations over the 10 major river basins (see Fig. 1 and Sect. 2.1 of the main text for the abbreviations) and China (CN) in DJF and JJA

\begin{tabular}{llllll}
\hline & \multicolumn{2}{l}{$\mathrm{T}\left({ }^{\circ} \mathrm{C}\right)$} & & $\mathrm{P}(\%)$ \\
\cline { 2 - 3 } \cline { 6 - 6 } & DJF & JJA & & DJF & JJA \\
\hline 1-SRB & $2.6 / 0.93$ & $-0.7 / 0.97$ & & $210 / 0.75$ & $11 / 0.77$ \\
2-LRB & $0.8 / 0.95$ & $-1.4 / 0.97$ & & $375 / 0.89$ & $33 / 0.70$ \\
3-HaiRB & $0.5 / 0.99$ & $-1.4 / 0.99$ & & $225 /-0.11$ & $67 /-0.08$ \\
4-YLB & $-0.7 / 0.97$ & $-1.5 / 0.99$ & & $236 / 0.60$ & $84 / 0.61$ \\
5-HRB & $1.0 / 0.95$ & $-1.1 / 0.94$ & & $23 / 0.94$ & $-5 / 0.09$ \\
6-YRB & $-2.0 / 0.98$ & $-0.6 / 0.99$ & $320 / 0.29$ & $29 / 0.38$ \\
7-ZRB & $-0.4 / 0.95$ & $-0.2 / 0.92$ & $38 /-0.22$ & $9 / 0.07$ \\
8-SERB & $-2.3 / 0.89$ & $-1.8 / 0.87$ & & $-12 / 0.39$ & $17 / 0.58$ \\
9-SWRB & $-5.3 / 0.99$ & $-1.9 / 0.98$ & & $795 / 0.37$ & $157 / 0.28$ \\
10-NWRB & $-0.3 / 0.81$ & $-0.1 / 0.99$ & & $545 / 0.55$ & $55 / 0.73$ \\
CN & $-0.8 / 0.94$ & $-0.7 / 0.98$ & & $389 / 0.46$ & $52 / 0.67$ \\
\hline
\end{tabular}

Correlation coefficients that are not statistically significant at the $95 \%$ confidence level are indicated by italic and SERB, respectively. Mean biases over whole of China in DJF and JJA are $-0.8{ }^{\circ} \mathrm{C}$ and $-0.7^{\circ} \mathrm{C}$, respectively.

The spatial correlation coefficients (CORs) between ensR and observations are also provided in Table 1 . The CORs are high, with only 6 of the total 20 river basin cases being < 0.95 , all statistically significant at the $95 \%$ confidence level using the equivalent sample size method (Zwiers and von Storch 1995).

Both ensR_QM (Fig. 2e, f) and ensR_QDM (Fig. 2g, h) reduce substantially the biases in DJF and JJA. The patterns of bias as well as the agreement among the ensemble members are very similar between ensR_QM and ensR_QDM in both seasons. In DJF (Fig. 2e, g), the biases are mostly within $\pm 1.0^{\circ} \mathrm{C}$ except in the region where the Yangtze and Yellow Rivers originate over the eastern part of the Tibetan Plateau. Smaller biases, within $\pm 0.5{ }^{\circ} \mathrm{C}$ are found in the Northeast and Northwest. A general cold bias prevails throughout the country but with lower agreement among the ensemble members. Regional mean biases over the different river basins and the whole of China for ensR_QM and ensR_QDM are close to 0 , and the CORs are all close to 1.00 thus they are not shown for brevity.

In JJA the biases are smaller than in DJF, mostly within $\pm 0.5^{\circ} \mathrm{C}$ (Fig. 2f, h). Cold biases ranging from $0.5^{\circ} \mathrm{C}$ to $1{ }^{\circ} \mathrm{C}$ are found in the mid and lower reaches of the Yangtze River basin and small portions over the Tibetan Plateau. Similar to DJF, close to 0 regional mean biases, and close to 1 CORs are found over the China river basins.

\subsection{Precipitation}

For precipitation, values greater than $200 \mathrm{~mm}$ in the Southeast and less than $50 \mathrm{~mm}$ over most of north and northwest China are observed in the dry season of DJF (Fig. 3a). In $\mathrm{JJA}$, the monsoon season, precipitation is more pronounced over the country with maxima exceeding $750 \mathrm{~mm}$ along the southern coastal regions (Fig. 3b).

The broad spatial patterns and magnitude of the precipitation biases in ensR show consistencies with those found when the model is driven by re-analysis fields (Gao et al. 2017). In DJF, there is an underestimation by $25-50 \%$ in the Southeast, where the precipitation center located, and a large overestimation, even in excess of $100 \%$, over the dry and mountainous regions of central and western China. The largest bias values over the river basins are found in SWRB and NWRB (Table 1). However, the uncertainties in the gridded observation dataset (due to the complex topography, lack of station observations over areas largely uninhabited, as well as the gauge undercatch of solid precipitation) may contribute to this large overestimation over the basins (Wu and Gao 2013; Gao et al. 2017). The smallest (negative) bias is found over SERB. The CORs between ensR and observations are 
(a) Observation in DJF, mm

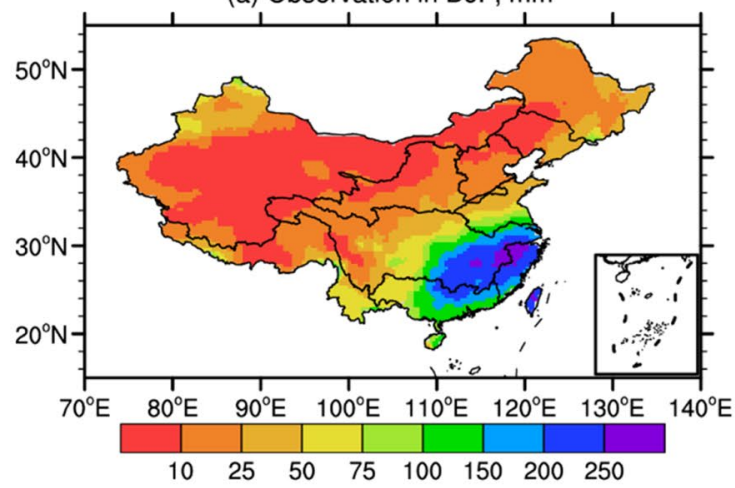

(c) Diff. of Pre. in DJF, ensR-CN05.1, \%

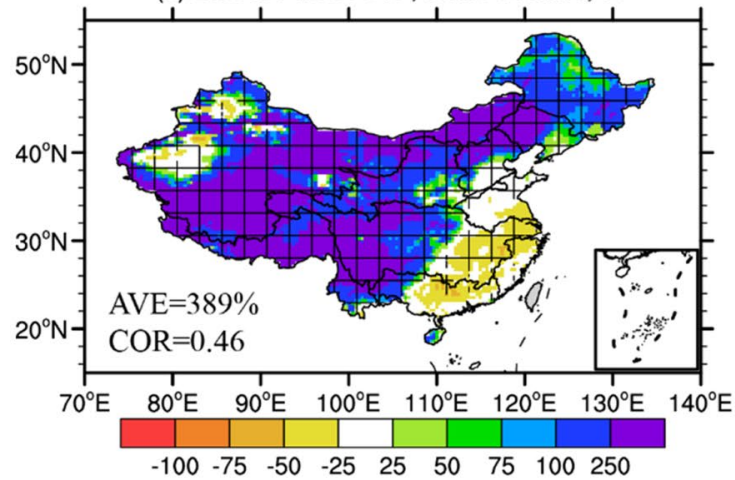

(e) Diff. of Pre. in DJF, ensR_QM-CN05.1, \%

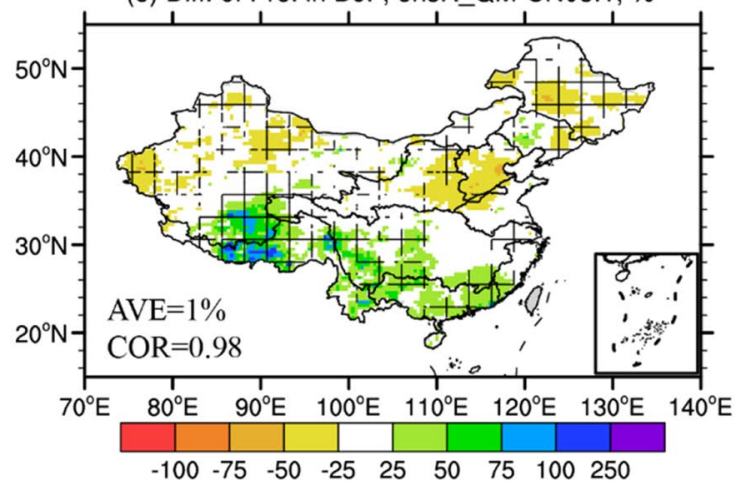

(g) Diff. of Pre. in DJF, ensR_QDM-CN05.1, \%

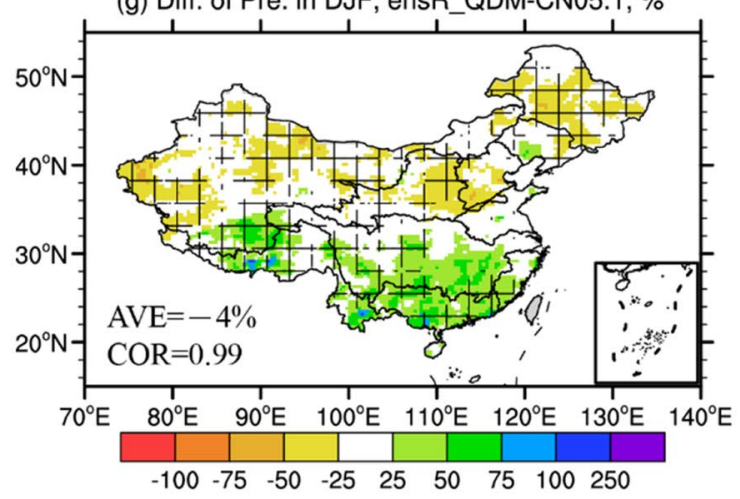

(b) Observation in JJA, mm

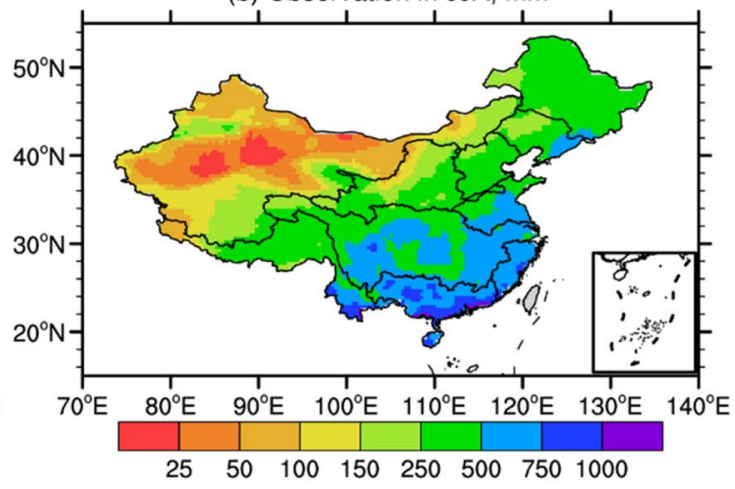

(d) Diff. of Pre. in JJA, ensR-CN05.1, \%

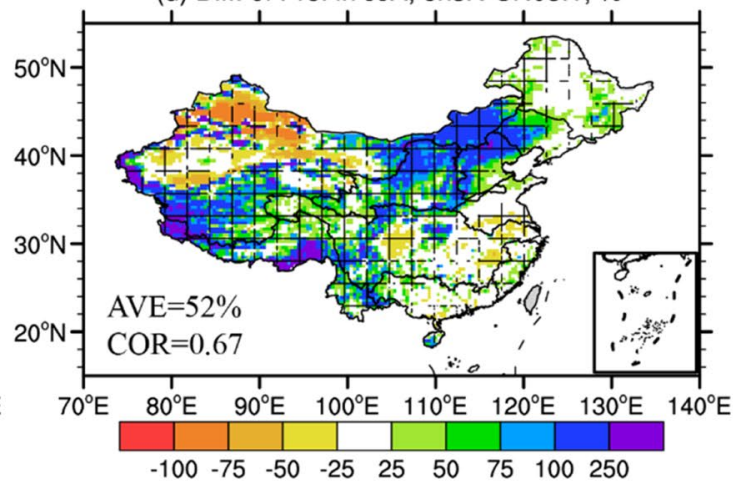

(f) Diff. of Pre. in JJA, ensR QM-CN05.1, \%

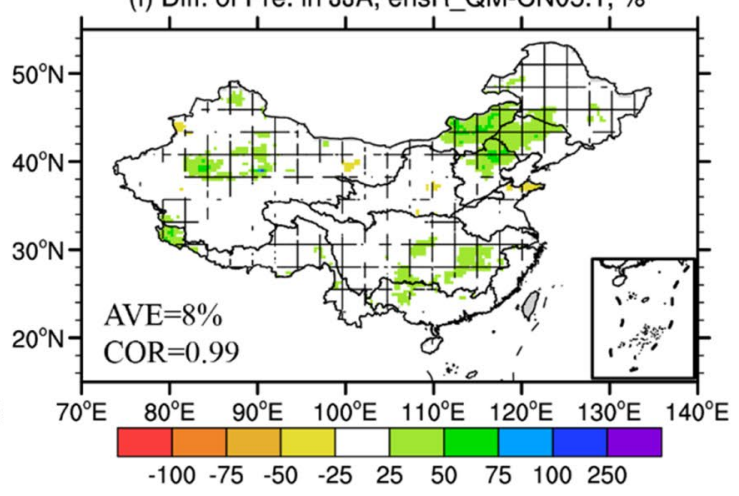

(h) Diff. of Pre. in JJA, ensR_QDM-CN05.1, \%

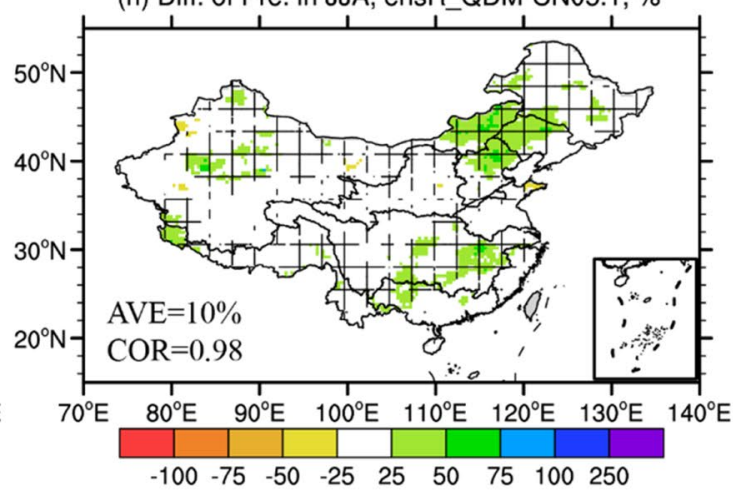

Fig. 3 Same as Fig. 2, but for precipitation (\%) 
statistically significant in 7 of the 10 basins, with a range of 0.29 to 0.94. In HaiRB and ZRB, negative CORs are found. The regional mean bias over whole of China is very large due to the contributions of the western basins, and the COR is 0.46 .

The bias of the ensR in JJA (Fig. 3d) is much smaller than in DJF, indicating a better performance of the model during the wet season. The main model bias is a large overestimation over the area extending from north HaiRB to Inner Mongolia, and an underestimation over the deserts in the Northwest. The biases are mostly positive in the river basins except HRB (Table 1). Greater than or close to $100 \%$ values are found in SWRB and YLB. A 50\% excess precipitation is simulated for the whole of China. The COR for the whole of China in JJA is 0.67 , greater than in DJF. However the CORs are statistically significant in only 6 out of the 10 basins, with close to zero values found in HaiRB, HRB, and ZRB. Thus the model reproduces the overall precipitation pattern for the whole country but not at the sub-regional river scale.

The biases are greatly reduced by both bias correction methods (Fig. 3e-h), more significantly in JJA, with the values of bias in most places within $\pm 25 \%$. Similar bias distribution patterns and magnitudes are found between ensR_ QM and ensR_QDM in both DJF and JJA. The mean biases over different basins are mostly within $\pm 25 \%$ in DJF and in the range of $-5 \sim 15 \%$ in JJA, respectively. The CORs are in general greater than 0.95 over the river basins, except ZRB with values around 0.60 and NWRB in the range of 0.80 to 0.90 (tables not shown for brevity). The regional mean biases over the whole of China for ensR_QM in DJF and JJA are $1 \%$ and $-4 \%$, and slightly larger for ensR_QDM, $8 \%$ and $9 \%$ for ensR_QDM, respectively. The CORs for the whole of China are generally high, in the range of 0.98 and 0.99 .

\section{Future climate change signals}

\subsection{Temperature}

\subsubsection{Projections by RegCM4}

Figure $4 \mathrm{a}, \mathrm{b}$ present the projected temperature changes at the end of the century (2079-2098) in DJF and JJA from ensR over China, while the mean changes over different river basins are reported in Fig. 5a, b. As can be seen, substantial warming is projected in both seasons. In DJF the warming is maximum over the Tibetan Plateau with values ranging from $3{ }^{\circ} \mathrm{C}$ to greater than $4{ }^{\circ} \mathrm{C}$ (Fig. 4a). This may be related to the stronger feedback between the warming and melting of snow cover over this cold region (Giorgi et al. 1997), and is considered as one of the added values of the downscaling as reported by $\mathrm{Wu}$ and Gao (2020). The warming in DJF is also large over the basins (deserts) in the Northwest $\left(>2.7^{\circ} \mathrm{C}\right)$. As indicated in Fig. 5a, b substantial spread across the river basins is found, with greatest warming around $3{ }^{\circ} \mathrm{C}$ in SWRB and NWRB and lowest warming of $2{ }^{\circ} \mathrm{C}$ in ZRB and HRB. The mean over the whole of China in DJF is $2.6^{\circ} \mathrm{C}$.

In JJA the warming is slightly weaker, with a mean value over China of $2.3^{\circ} \mathrm{C}$ (Fig. 4b). The warming is more evenly distributed in space for JJA compared to DJF, with a lower spread across the river basins, from $\sim 2$ to $\sim 2.5^{\circ} \mathrm{C}$ (Fig. 5 b). Larger values $\left(>2.4{ }^{\circ} \mathrm{C}\right)$ are found mostly over the region extending from LRB in the Northeast to the Northwest, as well as the northern part of the SWRB. Mean values over the river basins are largest in HaiRB and LRB and smallest in ZRB and SERB.

\subsubsection{Bias corrected projections using QM and QDM}

In DJF the ensR_QDM (Fig. 4e) shows very similar (and in fact almost same) values as ensR both in magnitude and spatial distribution, while large differences are found in ensR_QM (Fig. 4c). In ensR_QM the warming over the Tibetan Plateau is strongly reduced, as is the warming over the over Sichuan Basin. Figure 5 shows that in all basins the ensR_QM projects a lower warming than the original ensR, resulting in a mean warming over China in ensR_QM being reduced by $-0.3{ }^{\circ} \mathrm{C}$ with respect to ensR. The correlation between the ensR_QM and ensR warming patterns is 0.75 .

For the different river basins, Table 2 provides the differences and CORs for the temperature changes between ensR_QM and ensR at the end of 21st century. The biases of ensR_QDM are all close to 0 (see Fig. 5a) and the CORs close to 1 thus they are not provided for brevity. As shown in Table 2 and Fig. 5a, b general weakening of the warming is found over most river basins in DJF, except in HRB and ZRB with values close to 0 . The differences are larger, reaching half a degree, over NWRB, SWRB, and YRB. The CORs are mostly positive and statistically significant except in SERB and $\mathrm{ZRB}$, indicating that the original spatial patterns of the changes in most river basins are approximately kept.

Also in JJA the ensR_QDM maintains the original signal of ensR very well, while ensR_QM does not (Fig. 4f, d). The magnitude of the mean warming over China by ensR_QM is $-0.1^{\circ} \mathrm{C}$ lower than in ensR and the differences in the spatial distributions are large, with a COR value of about 0.32 . Differently from the general lowering of temperature in DJF by the $\mathrm{QM}$, a stronger warming is found in 3 out of the 10 river basins in JJA (Table 2; Fig. 5d). The maximum warming amplification is $0.4{ }^{\circ} \mathrm{C}$ over SERB, while the maximum 
(a) Change of Ts in DJF, ensR, ${ }^{\circ} \mathrm{C}$

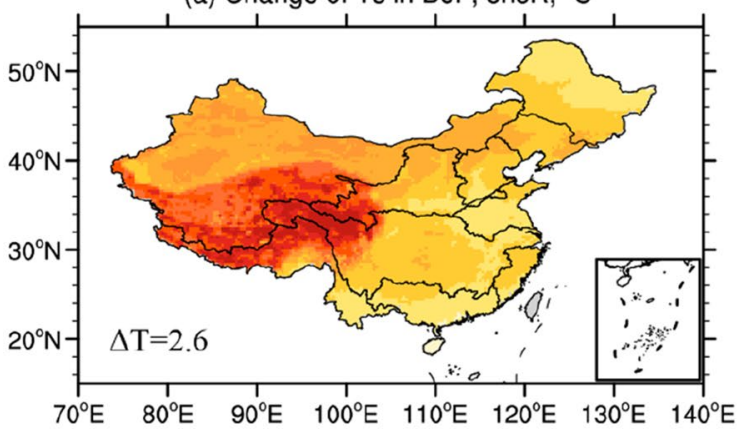

(c) Change of Ts in DJF, ensR_QM, ${ }^{\circ} \mathrm{C}$

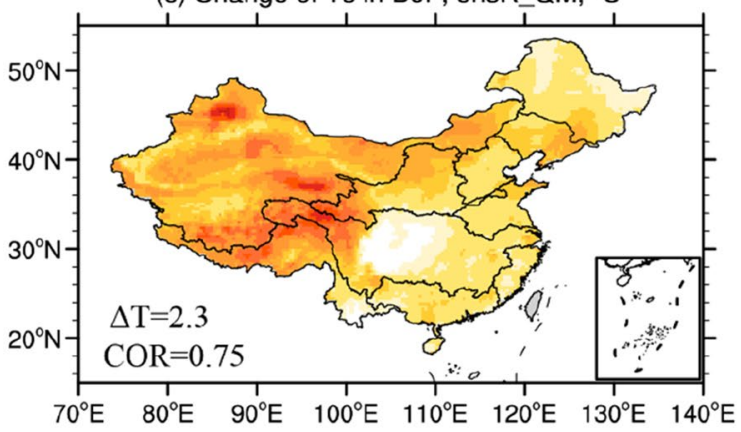

(e) Change of Ts in DJF, ensR_QDM, ${ }^{\circ} \mathrm{C}$

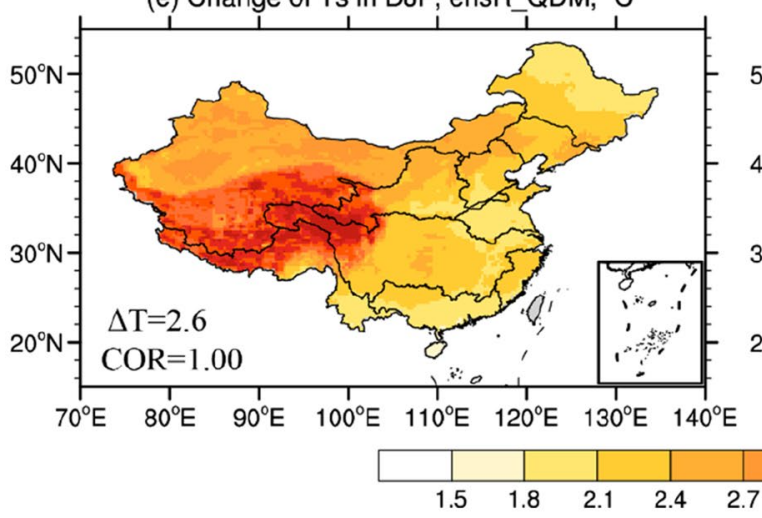

(b) Change of Ts in JJA, ensR, ${ }^{\circ} \mathrm{C}$

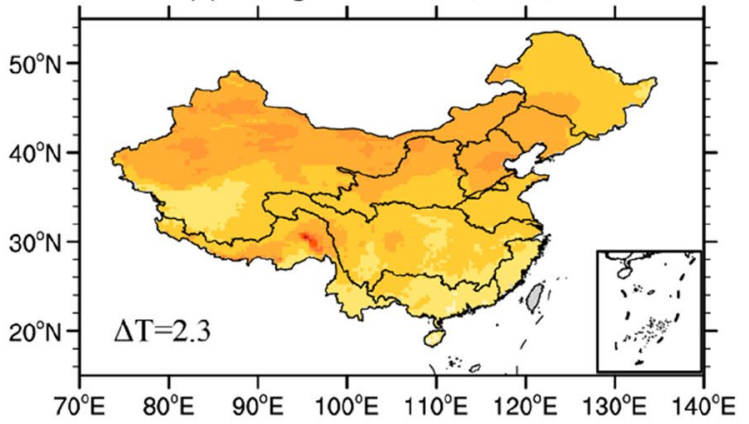

(d) Change of Ts in JJA, ensR_QM, ${ }^{\circ} \mathrm{C}$

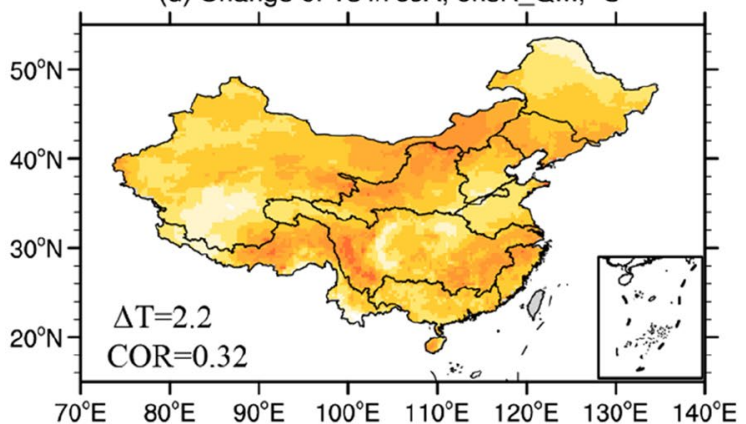

(f) Change of Ts in JJA, ensR_QDM, ${ }^{\circ} \mathrm{C}$

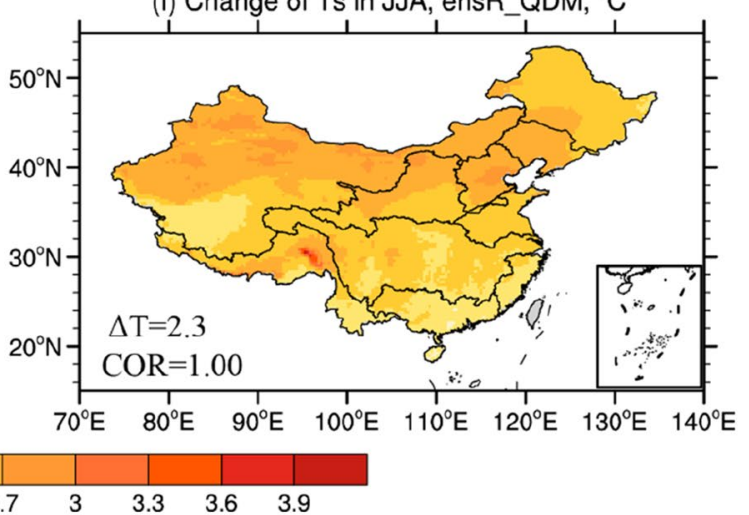

Fig. 4 Projected changes of temperature at the end of 21st century (2079-2098 in relative to $1986-2005$ ) (units: ${ }^{\circ} \mathrm{C}$ ): $\mathbf{a}$ ensR in DJF; b ensR in JJA; $\mathbf{c}$ ensR_QM in DJF; $\boldsymbol{d}$ ensR_QM in JJA; $\mathbf{e}$ ensR_QDM in DJF; $\mathbf{f}$ ensR_QDM in JJA. Regional mean over the whole of China and the CORs with ensR for $\mathbf{c}$ to $\mathbf{f}$ are provided in the lower left corner of the panels warming reduction is $-0.4{ }^{\circ} \mathrm{C}$ in HaiRB. CORs between ensR and ensR_QM JJA temperature change patterns are statistically significant in only 5 basins (YLB, SERB, SWRB, NWRB, and SRB). In summary, the QM method modifies significantly the temperature change signals from the original ensemble in both DJF and JJA, while the QDM method preserves it very closely.

\subsubsection{Results for individual simulations}

Figure 6 provides the projected and bias corrected model results for each of the 5 individual simulations in DJF.
The simulated temperature changes show large differences among the ensemble members (Fig. 6a1-5). As reported by Wu and Gao (2020), this can be largely attributed to the dependence on the driving GCMs and their climate sensitivities. Results from QDM show good consistencies with the original signal for all the simulations, both in the magnitude and spatial distribution (Fig. 6c1-5), while the signals are substantially modified in all the simulations using QM (Fig. 6b1-5). However the extent of this modification shows differences across the simulations.

While an overall lowering of the regional mean temperatures over China is found in all simulations, a larger 
(a) Change of Tm. in DJF

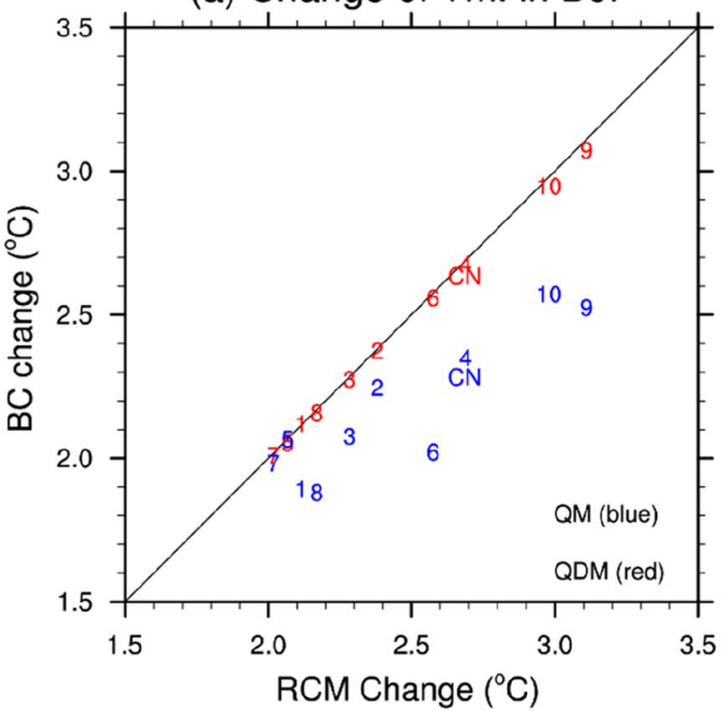

(c) Change of Pre. in DJF

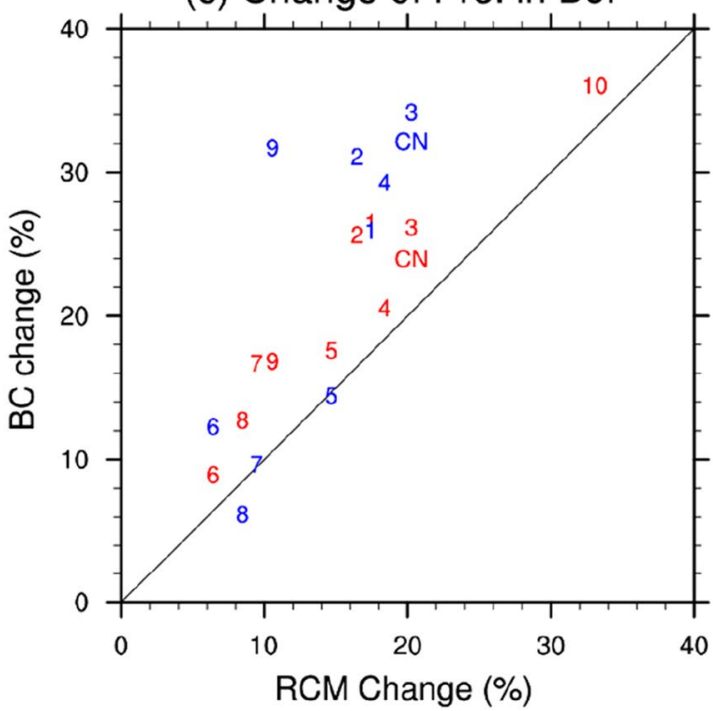

Fig. 5 Comparison of the temperature (unit: ${ }^{\circ} \mathrm{C}$ ) and precipitation (\%) change in ensR, ensR_QM and ensR_QDM at the end of 21st century over the 10 major river basins in China: a temperature in DJF; $\mathbf{b}$ temperature in JJA; $\mathbf{c}$ precipitation in DJF; $\mathbf{d}$ precipitation in JJA. The

decrease $\left(0.6{ }^{\circ} \mathrm{C}\right)$ is found for HdR_QM, followed by MdR_QM $\left(0.4{ }^{\circ} \mathrm{C}\right)$. Values for the rest of the realizations are in the range of $0.2-0.3{ }^{\circ} \mathrm{C}$. Concerning the CORs, the largest value of 0.90 is found for CdR_QM with the large warming over the Tibetan Plateau better preserved than in the other simulations (Fig. 6b1). The smallest value of COR is found in HdR_QM (0.71).

Similarly, in JJA (Fig. 7) the QDM preserves the temperature change signals very well for all simulations, differently from the QM. The weakening of the warming by (b) Change of Tm. in JJA

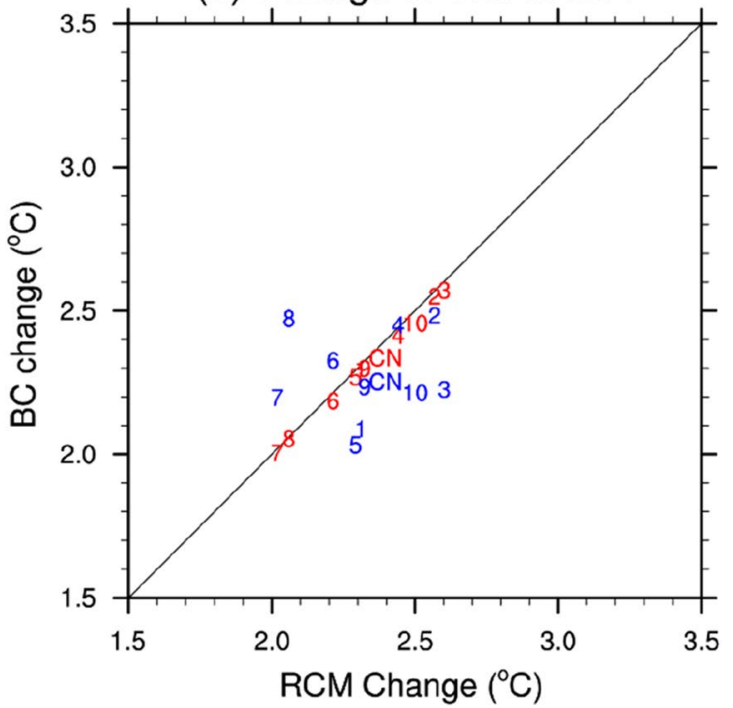

(d) Change of Pre. in JJA

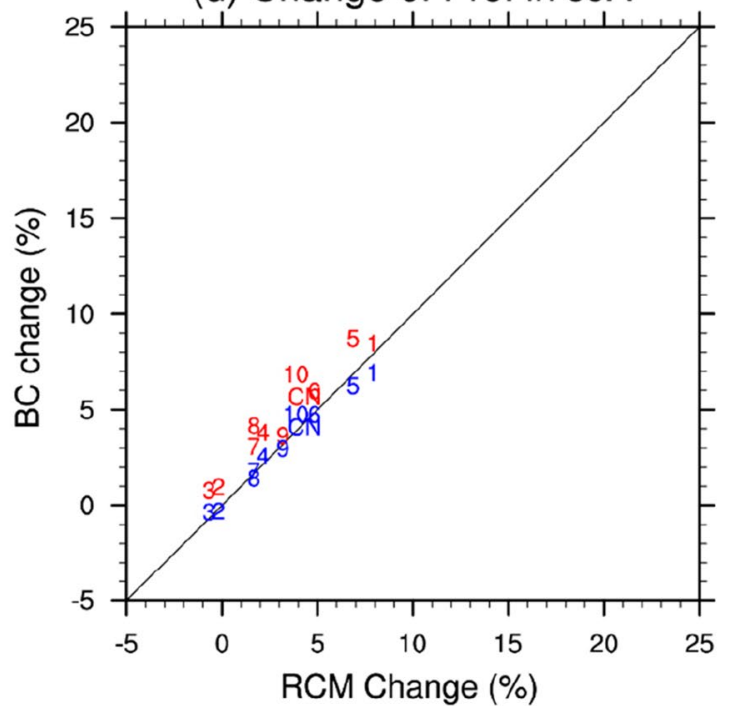

colored symbols indicate the different methods. The numbers indicate the different river basins as Fig. 1 with $\mathrm{CN}$ indicate the whole of China

QM is not as large as in DJF (Fig. 7b1-b5), with the largest magnitude of the warming reduction over China being $0.3{ }^{\circ} \mathrm{C}$ for MdR_QM, followed by $0.1^{\circ} \mathrm{C}$ for HdR_QM and NdR_QM. The values of warming remain unchanged in CdR_QM and EdR_QM. CORs of the individual simulations are close to 1 for QDM but in the range of $0.34-0.81$ for QM. It is noted than the COR between ensR and ensR_QM is only 0.32 , smaller than in all the individual simulations. 
Tabel 2 Differences and CORs of temperature changes (units: ${ }^{\circ} \mathrm{C}$ ) at the end of 21st century between ensR_QM and ensR over the 10 major river basins and China in DJF and JJA

\begin{tabular}{|c|c|c|c|c|}
\hline \multicolumn{5}{|l|}{$\mathrm{T}\left({ }^{\circ} \mathrm{C}\right)$} \\
\hline & \multicolumn{2}{|c|}{ Differences } & \multicolumn{2}{|l|}{ CORs } \\
\hline & DJF & JJA & DJF & JJA \\
\hline 1-SRB & -0.2 & -0.2 & 0.82 & 0.37 \\
\hline 2-LRB & -0.1 & -0.1 & 0.39 & -0.07 \\
\hline 3-HaiRB & -0.2 & -0.4 & 0.61 & 0.27 \\
\hline 4-YLB & -0.3 & 0.0 & 0.79 & 0.72 \\
\hline 5-HRB & 0.0 & -0.2 & 0.71 & -0.10 \\
\hline 6-YRB & -0.5 & 0.1 & 0.79 & 0.16 \\
\hline 7-ZRB & -0.0 & 0.2 & 0.14 & -0.22 \\
\hline 8-SERB & -0.3 & 0.4 & -0.17 & 0.64 \\
\hline 9-SWRB & -0.6 & -0.1 & 0.86 & 0.58 \\
\hline 10-NWRB & -0.4 & -0.2 & 0.41 & 0.52 \\
\hline $\mathrm{CN}$ & -0.3 & -0.1 & 0.75 & 0.32 \\
\hline
\end{tabular}

Correlations coefficients that are not statistically significant at the $95 \%$ confidence level are indicated by italic

\subsection{Precipitation}

\subsubsection{Projections by RegCM4}

Changes in precipitation from ensR, ensR_QM and ensR_ QDM in DJF and JJA at the end of the 21 st century are presented in Fig. 8. In both seasons and all ensembles a precipitation increase dominates throughout the country except for some small regions over the Northwest. In DJF, an increase of precipitation $>15 \%$ is found, except over areas extending from the Southwest to the middle reaches of the YRB (Fig. 8a). The relative change is largest over the dry basins in the Northwest, in excess of $50 \%$. The mean increase over China in DJF is $19 \%$. The spread of the increase is large across the river basins (Fig. 5c), with values of $<10 \%$ over YRB, SERB and ZRB, to over $30 \%$ over NWRB.

In JJA (Fig. 8b), the main regions with increased precipitation include the northern region of the Northeast (SRB), $\mathrm{HRB}$ and its adjacent areas in the west, and the eastern part of the Tibetan Plateau. The magnitudes of the increases are much lower than in DJF, in the range of $5-15 \%$. Little change or slight decreases of precipitation are found in the other areas. Consistently, the spread in different river basins in JJA is narrower than in DJF, in the range of close to 0 (HaiRB and LRB) to $~ 7 \%$ (SRB and HRB). The regional mean change in precipitation over the whole of China is a small increase of $3 \%$.

\subsubsection{Bias corrected projections using QM and QDM}

The change patterns of precipitation are in general preserved by both the QM and QDM methods in both seasons (Fig. 8c-f). In DJF, the corrections show a low impact with slight or negative changes (YRB and Southwest China), but tend to amplify the increases. This is more pronounced over western China in QM compared to QDM. The regional mean change over China using the QM is $32 \%$, which is about $7 \%$ higher than in the original model runs. CORs between ensR_QM and ensR_QDM with ensR in DJF are still high, as 0.81 and 0.93 , respectively.

Concerning the river basins, in excess of $20 \%$ more precipitation is found in SWRB and NWRB for ensR_QM compared to ensR (Table 3; Fig. 5c). The values are also large in LRB and HaiRB, about $15 \%$ and $14 \%$, respectively. The amplification of the increases is lower in ensR_QDM, ranging from 3 to $10 \%$ across the river basins. CORs between ensR_QDM and ensR are in general greater than in the case of ensR_QM over the basins. Statistically insignificant CORs are found in LRB and HaiRB in both ensR_QM and ensR_QDM.

In JJA (Fig. 8d, f), both methods preserve the original changes more strictly that in DJF. An amplification of the increase is found also in JJA by both QM and QDM but less pronounced than in DJF. In QDM, the decrease of precipitation over the basins in Northwest is converted to an increase. The mean precipitation increase over China for ensR_QM and ensR_QDM is 4\% and 6\%, respectively, thus close to the ensR value of $3 \%$. CORs are high, with values of 0.94 and 0.88 , respectively. Over the river basins, the differences compared to ensR for the QM and QDM methods are in the range of -1 to $2 \%$ and $1-4 \%$, respectively (Table 3 ; Fig. $5 \mathrm{~d}$ ). Lower than 0.90 COR (0.80) is found only in QDM over NWRB. In general, in JJA for precipitation the QM method preserves the change signal somewhat better than the QDM one.

\subsubsection{Results for individual simulations}

Figure 9 presents the projected precipitation changes from each of the 5 individual simulations and the corresponding bias corrected changes using the QM and QDM methods. In agreement with the ensemble mean, the projected wet-dry patterns are in general well preserved by both methods. The bias corrections tend to amplify the projected increase of precipitation in all runs, more significantly in QDM. The magnitudes and spatial distribution of the areas of precipitation reduction are also well kept, except in NdR_QDM over the lower reaches of the YRB, where a more extended decrease is found. The greatest precipitation amplification 

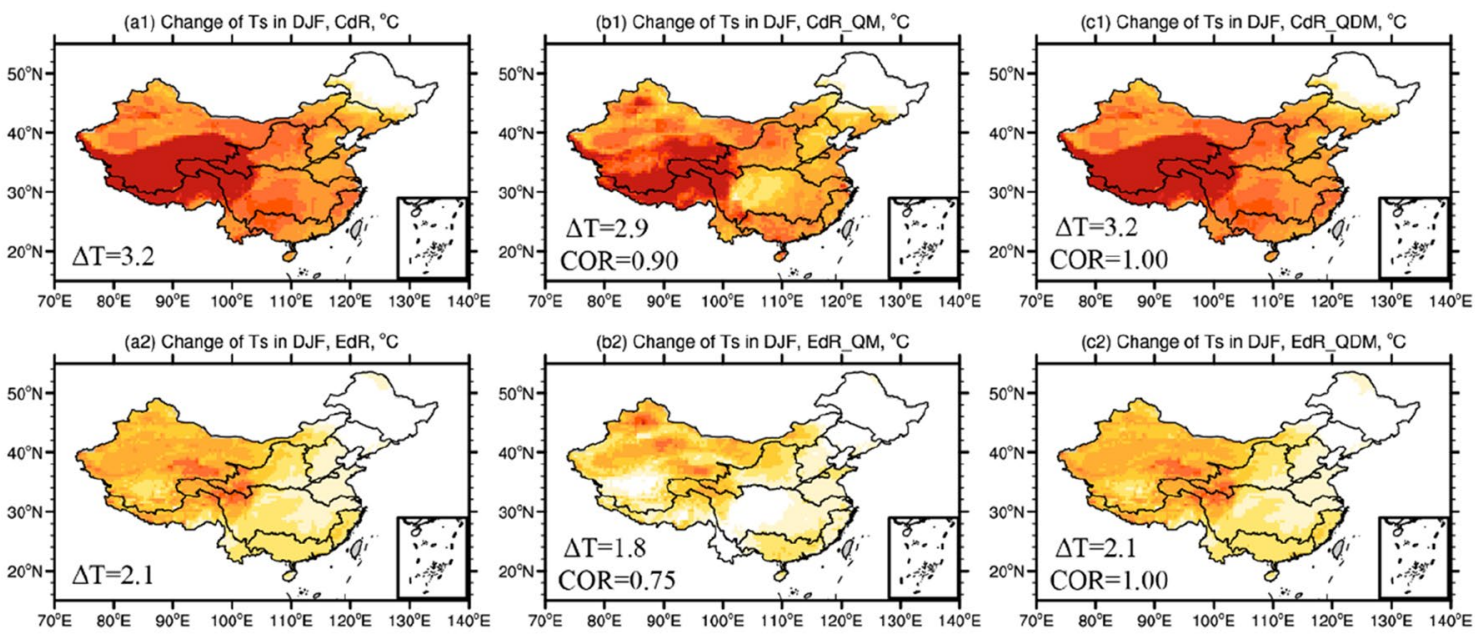

(c2) Change of Ts in DJF, EdR_QDM, ${ }^{\circ} \mathrm{C}$
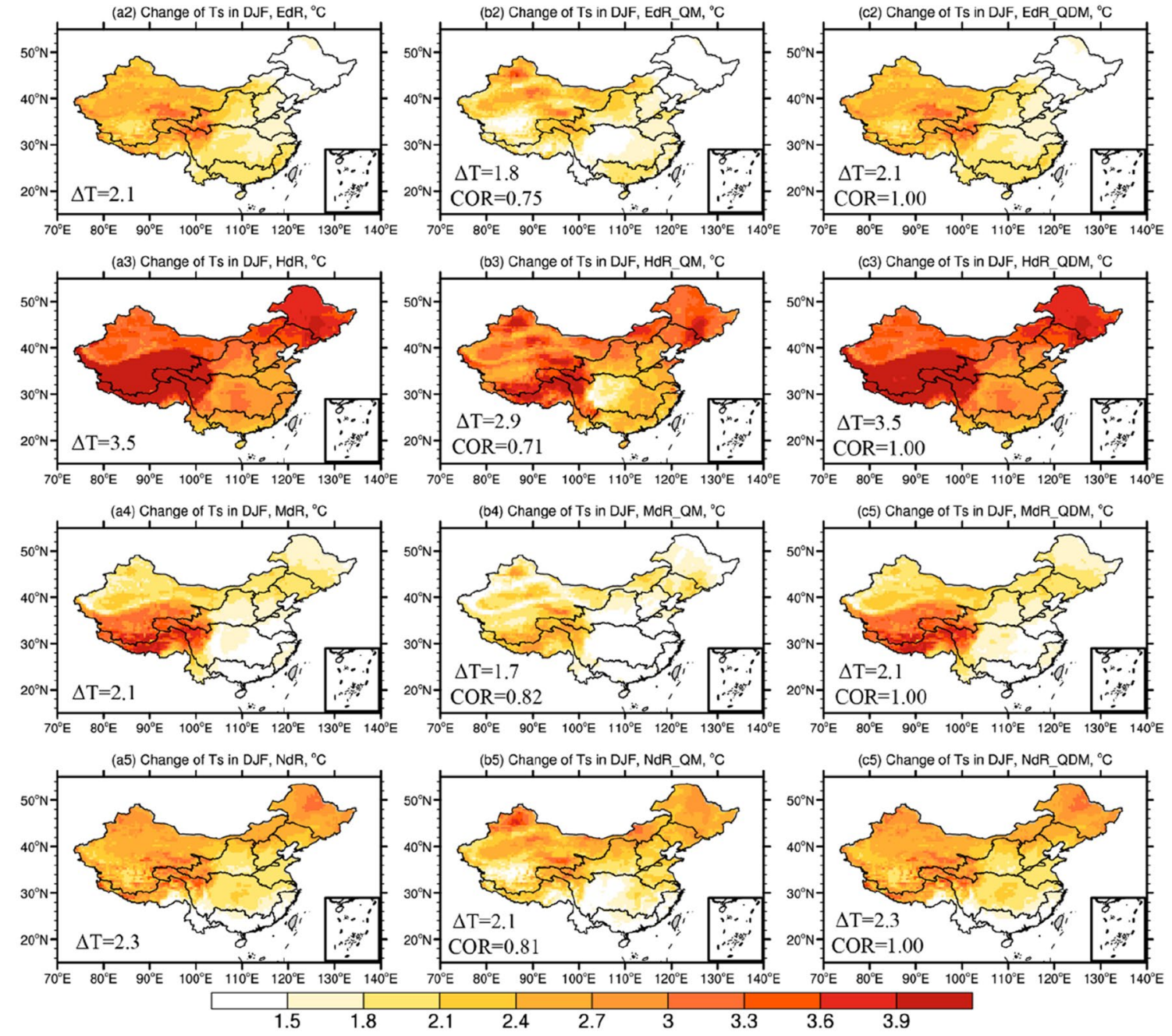

Fig. 6 Projected changes of temperature by the individual simulations and bias correction of them at the end of 21 st century in DJF (unit: ${ }^{\circ} \mathrm{C}$ ): a the original simulations; $\mathbf{b}$ corrected by QM; $\mathbf{c}$ corrected by QDM; (1-5) indicates RegCM4 simulation driven by different

GCMs. Regional mean over the whole of China for a to $\mathbf{c}$ and the CORs with original model projection for $\mathbf{b}$ to $\mathbf{c}$ are provided in the lower left corner of the panels

is found in HdR_QM, a simulation for which we also find the smallest COR with the original model projection (0.68). In JJA, the precipitation change signals for the individual runs are all well preserved by both methods (not provided for brevity).

\subsection{Annual cycles}

Figure 10a, b compare the annual cycle of monthly mean temperature and precipitation changes from the ensR, ensR QM and ensR_QDM over China by the end of the 21st century. For temperature in ensR (Fig. 10a), greater warming in 

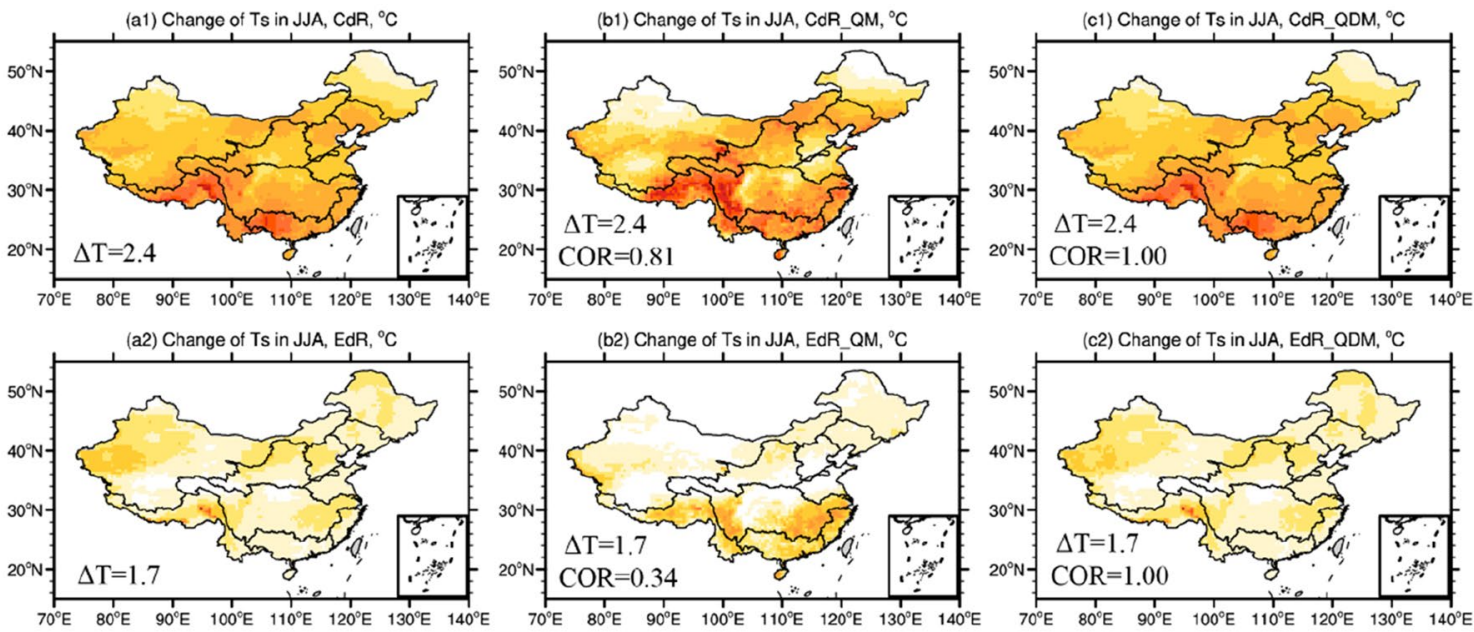

(c2) Change of Ts in JJA, EdR_QDM, ${ }^{\circ} \mathrm{C}$
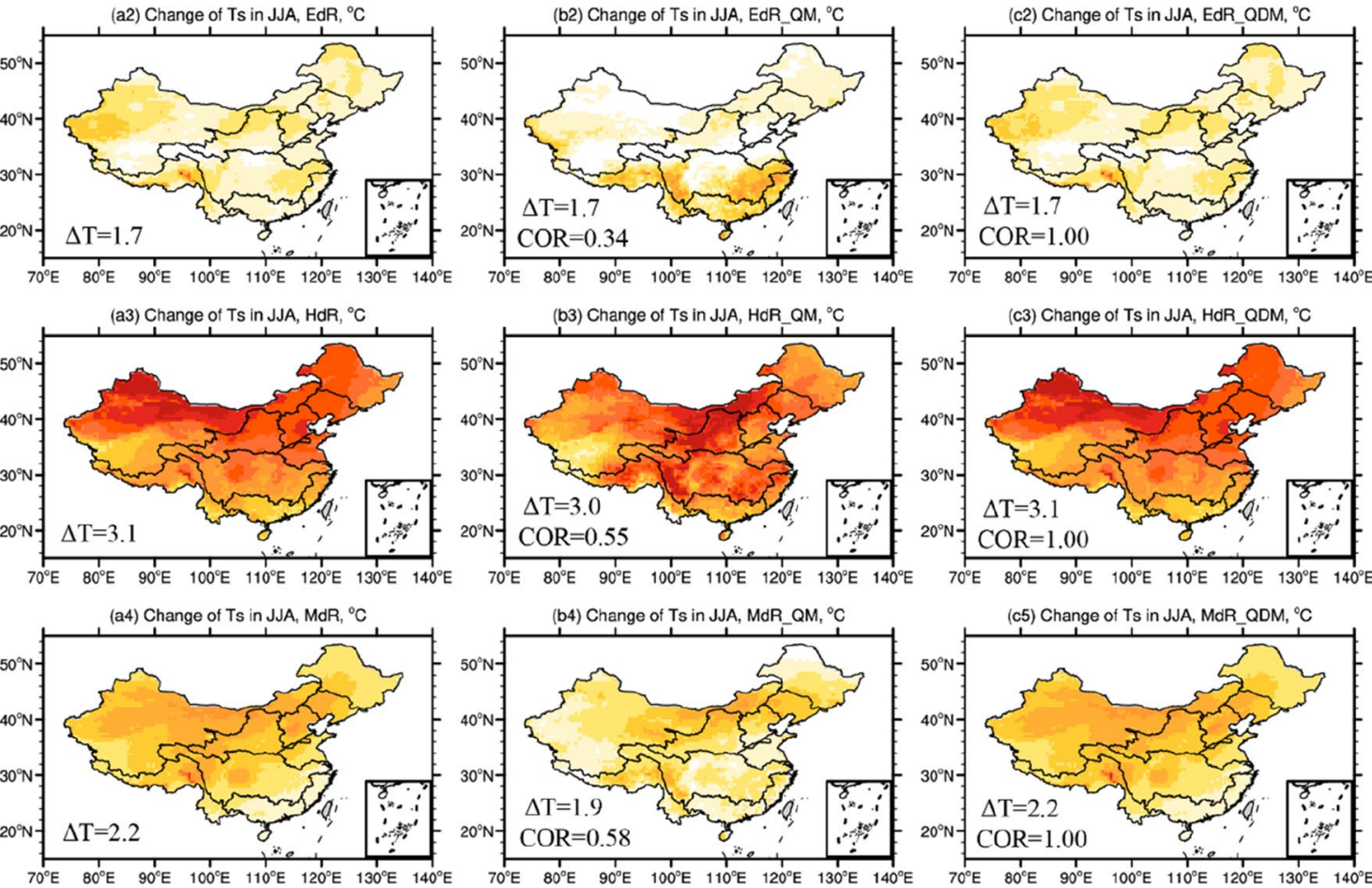

(b4) Change of Ts in JJA, MdR_QM, ${ }^{\circ} \mathrm{C}$
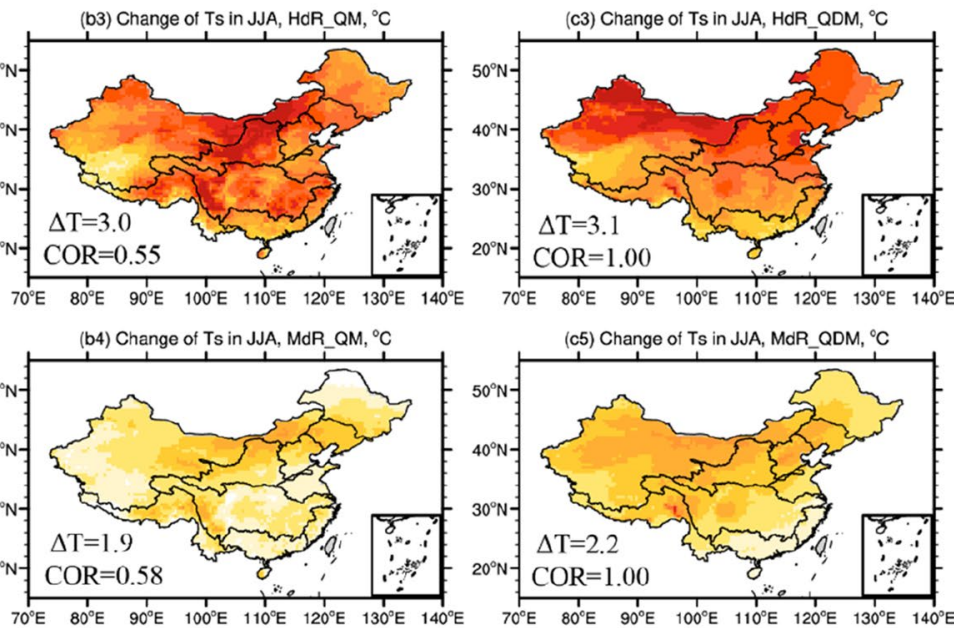

(c5) Change of Ts in JJA, MdR_QDM, ${ }^{\circ} \mathrm{C}$
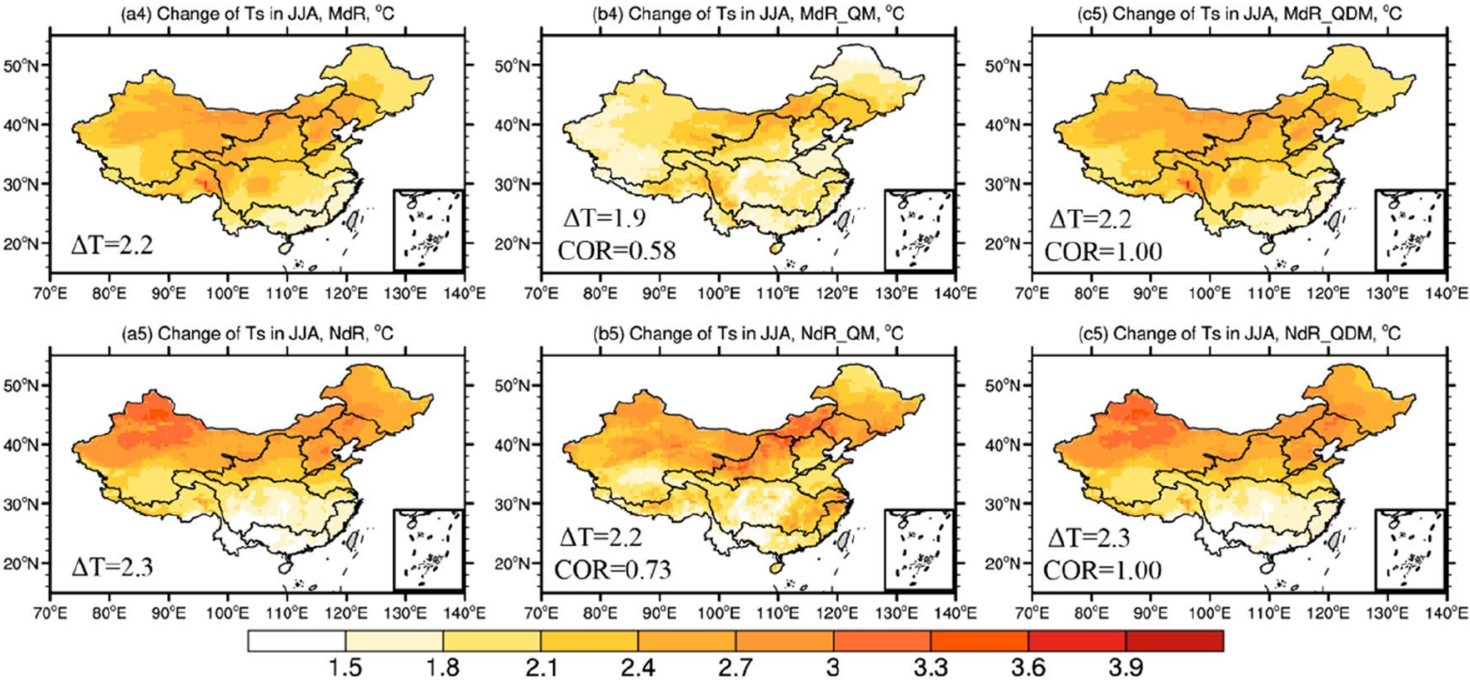

Fig. 7 Same as Fig. 6, but for JJA

the range of $2.6-2.8{ }^{\circ} \mathrm{C}$ is found during the winter months, from November to February, with a maximum in November. The warming is the lowest in the spring months, May and April, with values of $1.9{ }^{\circ} \mathrm{C}$ and $2.0{ }^{\circ} \mathrm{C}$, respectively. Interestingly, the warming has a peak also in august, with a value of $2.5^{\circ} \mathrm{C}$.

While the QDM keeps the magnitude of warming very closely in all months, the QM reduces the warming in 7 months of the year, especially in the winter months, about
$0.4{ }^{\circ} \mathrm{C}$ in January and $0.3{ }^{\circ} \mathrm{C}$ in December and February. Only in April and May the QDM produces a higher warming than ensR by about $0.1^{\circ} \mathrm{C}$.

For precipitation (Fig. 10b), the largest increases are projected in ensR during the colder and drier part of the year, from October to April, in the range of 10-25\%. Increases of $<5 \%$ are found in the summer monsoon months. The shape of the annual cycle of precipitation change in ensR is reproduced by both ensR_QM and ensR_QDM, however 
(a) Change of Pre. in DJF, ensR, \%

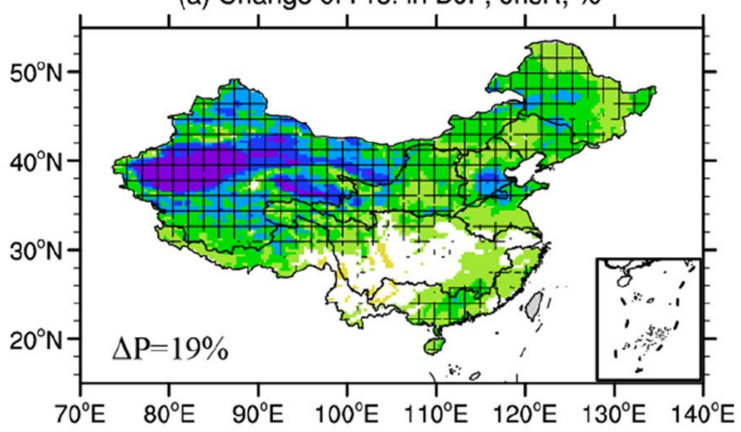

(c) Change of Pre. in DJF, ensR_QM, \%

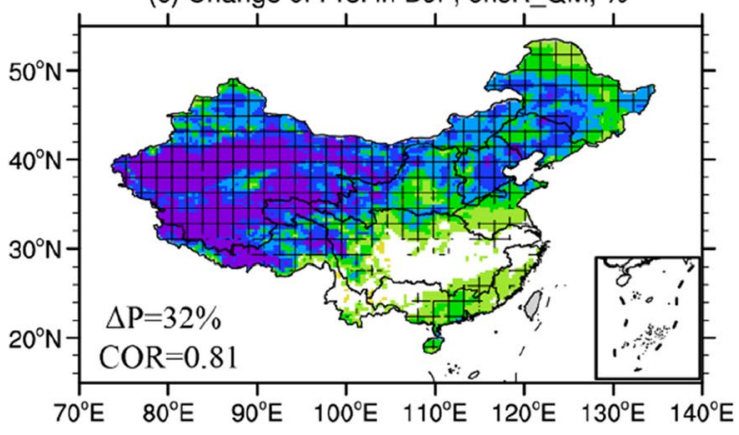

(e) Change of Pre. in DJF, ensR_QDM, \%

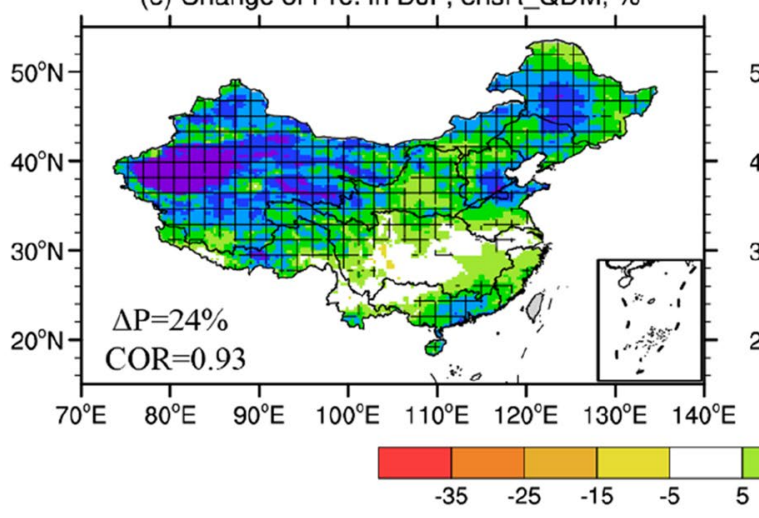

(b) Change of Pre. in JJA, ensR, \%

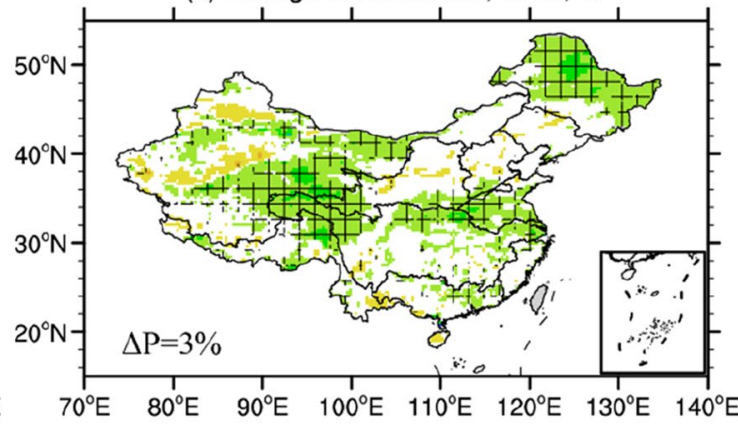

(d) Change of Pre. in JJA, ensR_QM, \%

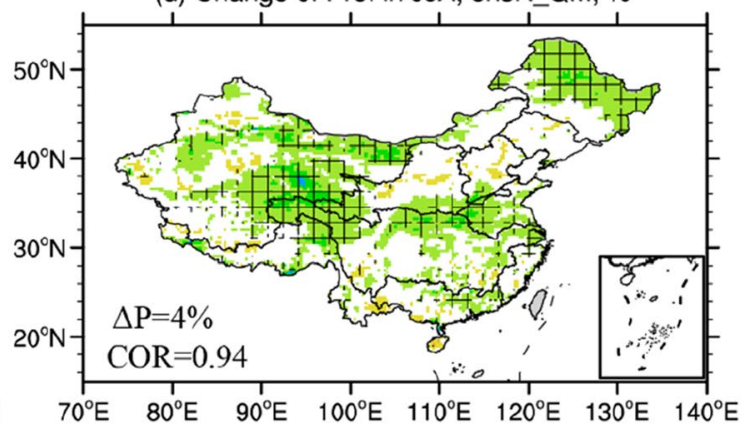

(f) Change of Pre. in JJA, ensR_QDM, \%

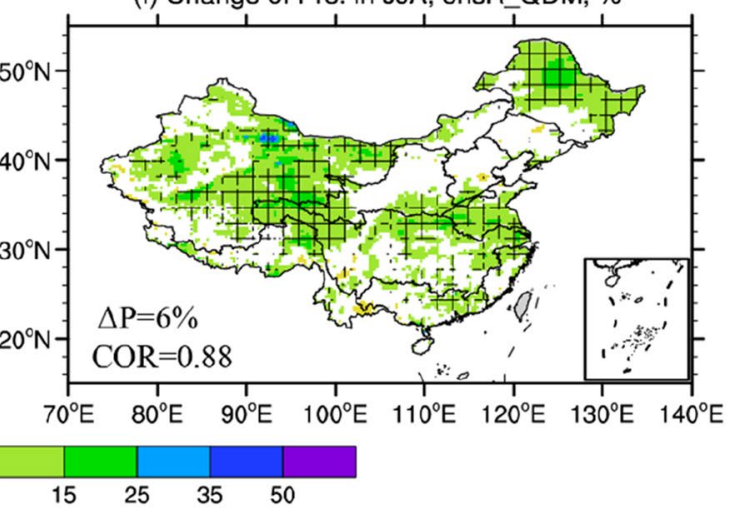

Fig. 8 Same as Fig. 4, but for precipitation (\%)

both bias correction methods tend to amplify the precipitation increases, except for the three summer months. In general, the QM method produces a larger amplification of the precipitation increase than the QDM, up to about $15 \%$ amplification in the winter months.

\section{Conclusions and discussion}

In this paper, we apply the QM and QDM bias correction methods to a series of RegCM4 downscaled projections driven by 5 CMIP5 models over East Asia. The simulated present day climate biases and validation for the two methods are first presented, followed by an analysis of the change signals. Our focus of is on the mean temperature and precipitation in DJF and JJA over China. This is the first study that intercompares different bias-correction methods applied to an ensemble of RCM projections to increase robustness of the results.

The biases of ensR for the present day climate simulation period show consistencies with the model driven by other GCMs and re-analysis fields (Gao and Giorgi 2017; Gao et al. 2017). The RegCM4 is characterized by a warm bias in DJF at high latitudes of northern China and a cold 
Tabel 3 Differences and CORs of precipitation changes (\%) at the end of 21st century between ensR_QM/ensR_QDM and ensR over the 10 major river basins and China in DJF and JJA

\begin{tabular}{llllll}
\hline $\mathrm{P}(\%)$ & \multicolumn{3}{l}{$l$} \\
\cline { 1 - 2 } & \multicolumn{2}{l}{ Differences } & & \multicolumn{2}{l}{ CORs } \\
\cline { 2 - 3 } & DJF & JJA & & DJF & JJA \\
\hline 1-SRB & $9 / 9$ & $-1 / 1$ & & $0.83 / 0.85$ & $0.97 / 0.98$ \\
2-LRB & $15 / 10$ & $0 / 1$ & & $0.62 / 0.70$ & $0.92 / 0.96$ \\
3-HaiRB & $14 / 6$ & $1 / 2$ & & $0.51 / 0.89$ & $0.95 / 0.95$ \\
4-YLB & $11 / 3$ & $1 / 2$ & & $0.72 / 0.78$ & $0.98 / 0.97$ \\
5-HRB & $0 / 3$ & $0 / 2$ & & $0.93 / 0.93$ & $0.96 / 0.92$ \\
6-YRB & $6 / 3$ & $0 / 1$ & & $0.73 / 0.91$ & $0.95 / 0.96$ \\
7-ZRB & $1 / 8$ & $0 / 2$ & & $0.89 / 0.85$ & $0.97 / 0.94$ \\
8-SERB & $-2 / 5$ & $0 / 3$ & & $0.73 / 0.56$ & $0.94 / 0.92$ \\
9-SWRB & $22 / 7$ & $0 / 1$ & & $0.68 / 0.78$ & $0.94 / 0.98$ \\
10-NWRB & $20 / 4$ & $2 / 4$ & & $0.70 / 0.92$ & $0.93 / 0.80$ \\
CN & $13 / 5$ & $1 / 3$ & & $0.81 / 0.93$ & $0.94 / 0.88$ \\
\hline
\end{tabular}

Correlation coefficients that are not statistically significant at the $95 \%$ confidence level are indicated by italic

bias over the Tibetan Plateau, along with an underestimate of precipitation in the Southeast and an overestimate in the dry north. In JJA, a warm bias is found over the deserts of the Northwest and a cold bias prevails elsewhere, while the precipitation climatology is better simulated than in DJF.

These biases are effectively removed by both the QM and QDM methods, although some differences with observations still remain. However, these are small and show consistency between the methods so that it is not possible to establish which method is better in this respect. Concerning the future changes, substantial warming is projected in ensR, greater in DJF than in JJA. While the QDM preserves very closely the change signal of ensR both in spatial distribution and magnitude, substantial distortions are found when using the QM, which produces lower warming and some modifications in the patterns of change. These effects are more pronounced in DJF than $\mathrm{JJA}$, and are found in all individual simulations of the ensemble.

Concerning the projected precipitation, a prevailing increase is found north of $30^{\circ} \mathrm{N}$, with greatest magnitude over the Northwest basins in DJF. In JJA over eastern China, the precipitation change shows areas of alternative positive and negative changes moving from north to south, but a prevailing increase of precipitation. The patterns of precipitation change are in general preserved by both the QM and QDM methods, which however tend to amplify the precipitation increases. This amplification is more pronounced during the winter months and by the QM method.

In summary, the QDM method is shown to preserve better the change signal for temperature in both seasons and for precipitation in the winter (dry season). In summer the two methods exhibit more similar results. An important conclusion of our analysis is that the magnitude of the projected changes can be substantially affected by the bias correction, and depend on the method adopted, the season and the variable analyzed. For example, the QM method produces much larger precipitation changes and lower warming levels in the winter compared to the original RCMs, with both effects considerably reduced by the QDM method. This highlights the fact that care has to be taken in performing bias correction of model data, as this adds a further layer of uncertainty in regional climate projections. Different methods should be tested for given model applications and the final choice of method may depend on the specific objectives of a given application. Adding a correction factor as proposed by Pierce et al. (2015) may also be an effective method to make sure that the change in seasonal mean values are well preserved, and this issue will be explored in future work.

Our final goal is to construct a bias corrected climate change dataset over China based on the series of RegCM4 simulations for impact studies. As a starting point, we have focused the analysis on the mean climatology. However, for example, the amplification of the projected precipitation increase may be at least partly due to the amplified heavy precipitation increase by both the QM and QDM methods, which accounts for a large proportion of the total precipitation amount over China (Zhai et al. 2005). Therefore further investigations on daily statistics and extreme events is needed and will be carried out in future work. 

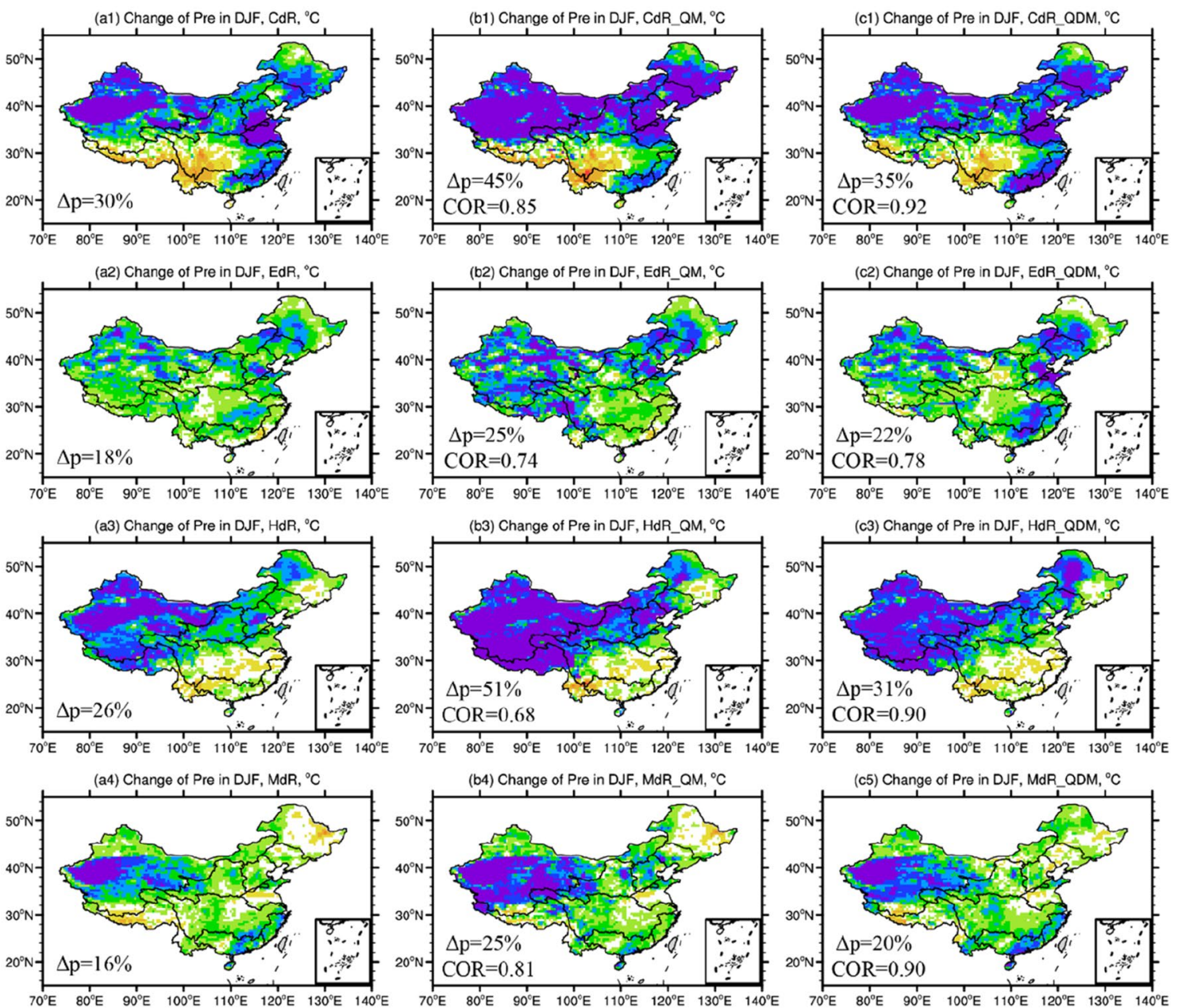

(b4) Change of Pre in DJF, MdR_QM, ${ }^{\circ} \mathrm{C}$
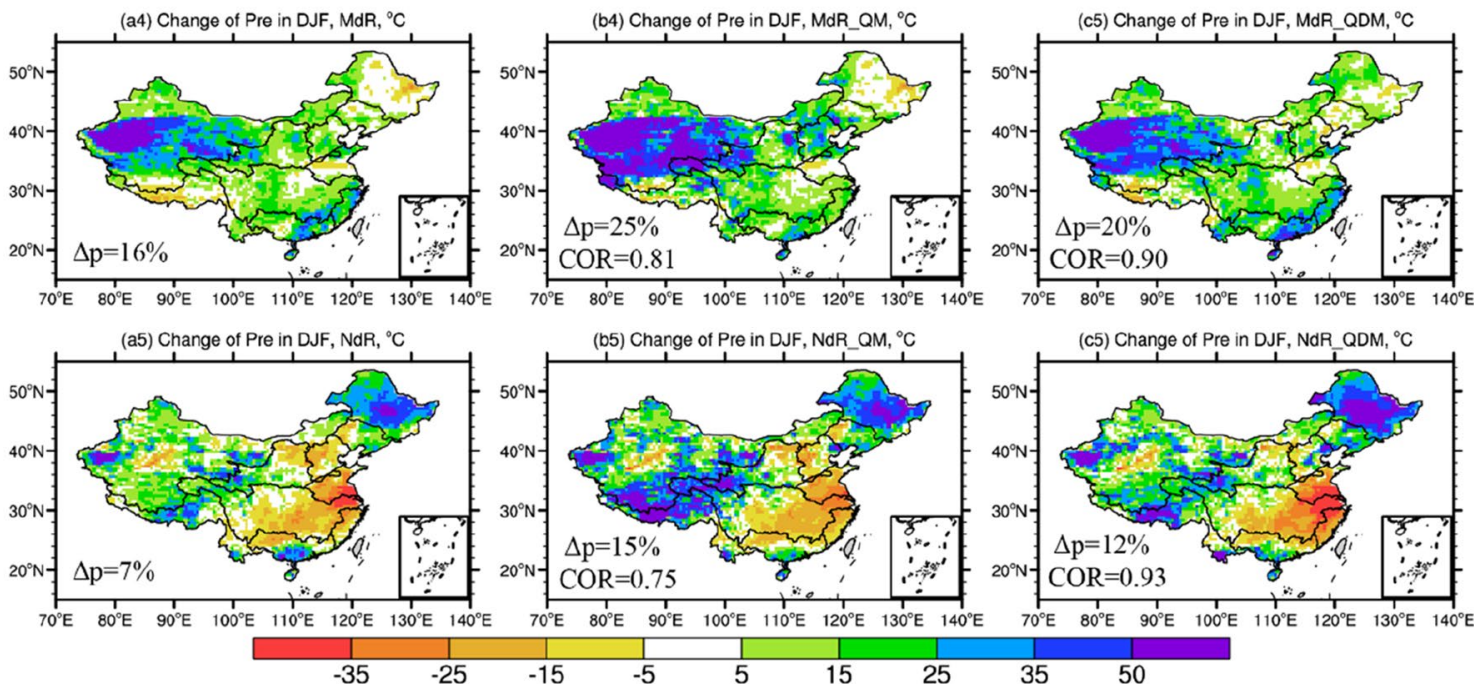

\begin{tabular}{llllll} 
& & & & \\
\hline
\end{tabular}
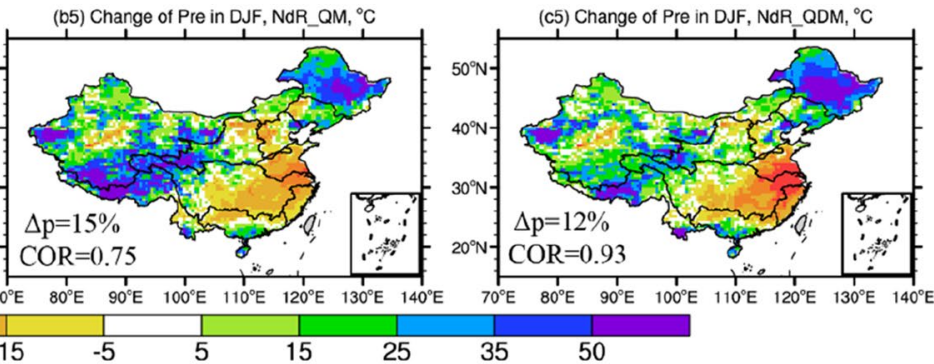

25

35

Fig. 9 Same as Fig. 6, but for precipitation (\%) 
Fig. 10 The annual cycle of monthly mean temperature (a; units: ${ }^{\circ} \mathrm{C}$ ) and precipitation changes $(\mathbf{b} ; \%)$ at the end of 21 st century over China ensR (black), ensR_QM (blue) and ensR_QDM (red)
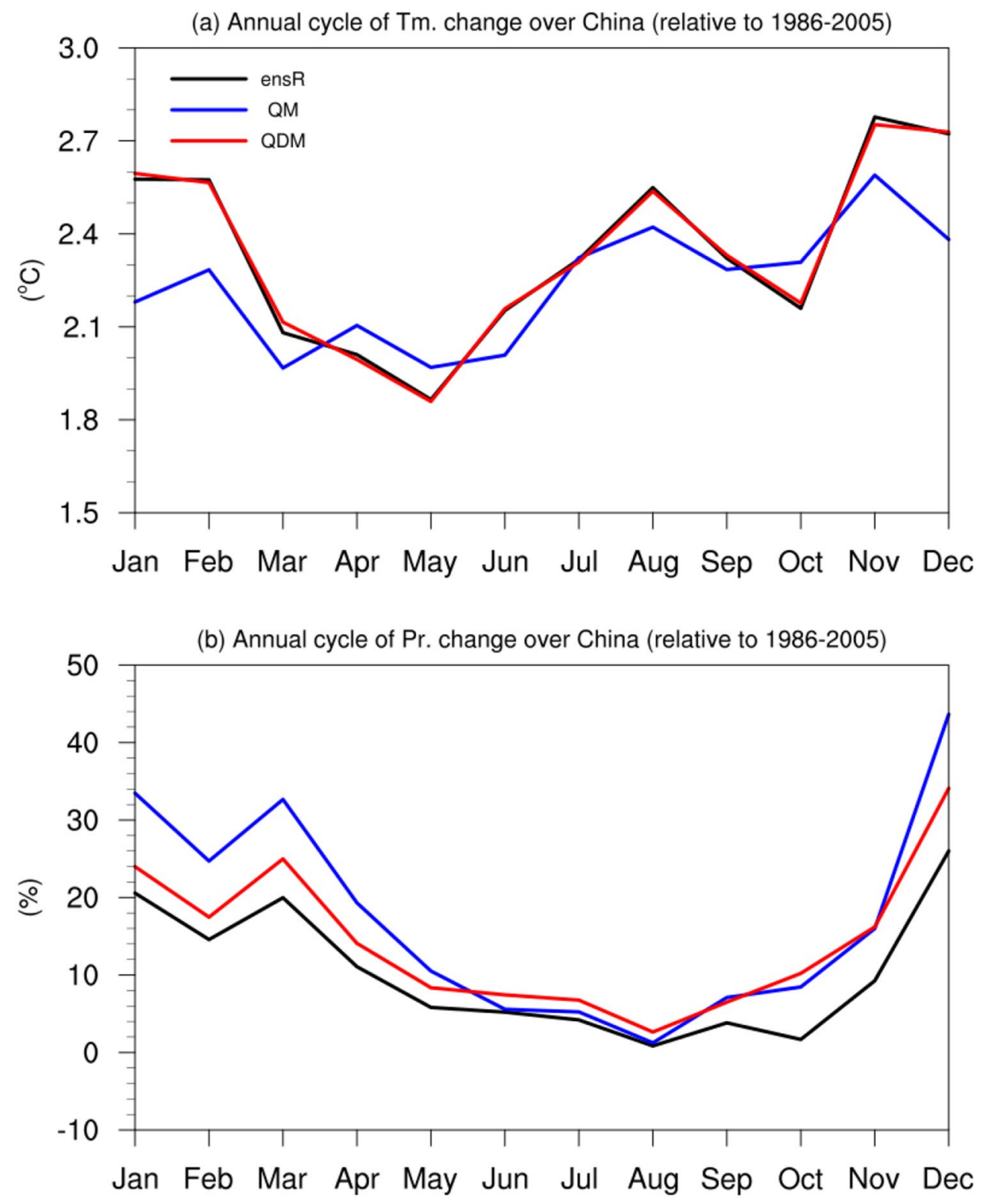

Acknowledgements This research was jointly supported by the National Key Research and Development Program (Grant No. 2016YFA0600704), National Natural Science Foundation of China (Grant No. 41991284), and the Science and Technology Program of Yunnan "Impact assessments and monitor-forecasting technology of meteorological disasters for Yunnan Plateau characteristic agriculture under climate change" (Grant No. 2018BC007).

Open Access This article is licensed under a Creative Commons Attribution 4.0 International License, which permits use, sharing, adaptation, distribution and reproduction in any medium or format, as long as you give appropriate credit to the original author(s) and the source, provide a link to the Creative Commons licence, and indicate if changes were made. The images or other third party material in this article are included in the article's Creative Commons licence, unless indicated otherwise in a credit line to the material. If material is not included in the article's Creative Commons licence and your intended use is not permitted by statutory regulation or exceeds the permitted use, you will need to obtain permission directly from the copyright holder. To view a copy of this licence, visit http://creativecommons.org/licenses/by/4.0/.

\section{References}

Ahmed KF, Wang G, Silander J, Wilson AM, Allen JM, Horton R, Anyah R (2013) Statistical downscaling and bias correction of climate model outputs for climate change impact assessment in the U.S. northeast. Global Planet Change 100:320-332

Ashfaq M, Bowling LC, Cherkauer K, Pal JS, Diffenbaugh NS (2010) Influence of climate model biases and daily-scale temperature and precipitation events on hydrological impacts assessment: a case study of the United States. J Geophys Res 115:D14

Bentsen M, Bethke I, Debernard J et al (2013) The Norwegian earth system model, NorESM1-M-Part 1: description and basic evaluation of the physical climate. Geosci Model Dev 6:687-720 
Boé J, Terray L, Habets F, Martin E (2007) Statistical and dynamical downscaling of the Seine basin climate for hydro-meteorological studies. Int J Climatol 27:1643-1655

Bürger G, Murdock TQ, Werner AT, Sobie SR, Cannon AJ (2012) Downscaling extremes - an intercomparison of multiple statistical methods for present climate. J Clim 25:4366-4388

Bürger G, Sobie SR, Cannon AJ, Werner AT, Murdock TQ (2013) Downscaling extremes: an intercomparison of multiple methods for future climate. J Clim 26:3429-3449

Cannon AJ, Sobie SR, Murdock TQ (2015) Bias correction of $\mathrm{gcm}$ precipitation by quantile mapping: how well do methods preserve changes in quantiles and extremes? J Clim 28:6938-6959

Collins WJ, Bellouin N, Doutriaux-Boucher M et al (2011) Development and evaluation of an earth-system model-HadGEM2. Geosci Model Dev 4:1051-1075

Eden JM, Widmann M, Grawe D, Rast S (2012) Skill, correction, and downscaling of GCM-simulated precipitation. J Clim 25:3970-3984

Gao XJ, Giorgi F (2017) Use of the RegCM system over East Asia: review and perspectives. Engineering 3(5):766-772

Gao XJ, Xu Y, Zhao ZC, Pal JS, Giorgi F (2006) On the role of resolution and topography in the simulation of East Asia precipitation. Theoret Appl Climatol 86:173-185

Gao XJ, Shi Y, Zhang DF, Wu J, Giorgi F, Ji ZM, Wang YG (2012) Uncertainties of monsoon precipitation projection over China: results from two high resolution RCM simulations. Clim Res $52: 213-226$

Gao XJ, Shi Y, Giorgi F (2016) Comparison of convective parameterizations in RegCM4 experiments over China with CLM as the land surface model. Atmos Oceanic Sci Lett 9:246-254

Gao XJ, Shi Y, Han ZY, Wang ML, Wu J, Zhang DF, Xu Y, Giorgi F (2017) Performance of RegCM4 over major river basins in China. Adv Atmos Sci 34:441-455

Gao XJ, Wu J, Shi Y, Wu J, Han ZY, Zhang DF, Tong Y, Li RK, Xu Y, Giorgi F (2018) Future changes in thermal comfort conditions over China based on multi-RegCM4 simulations. Atmos Oceanic Sci Lett 11:291-299

Giorgi F (2019) Thirty years of regional climate modeling: where are we and where are we going next? J Geophys Res Atmos 124(11):5696-5723

Giorgi F, Hurrell JW, Marinucci MR, Beniston M (1997) Elevation dependency of the surface climate change signal: a model study. J Clim 10:288-296

Giorgi F, Jones C, Asrar G (2009) Addressing climate information needs at the regional level: the CORDEX framework. WMO Bull 58:175-183

Giorgi F, Coppola E, Solmon F et al (2012) RegCM4: model description and preliminary tests over multiple CORDEX domains. Clim Res 52:7-29

Gudmundsson L (2012) qmap: statistical transformations for postprocessing climate model output. R package version 1.0-3. Available online at https://cran.r-project.org/web/packages/qmap/.

Gudmundsson L, Bremnes JB, Haugen JE, Engen-Skaugen T (2012) Technical note: downscaling RCM precipitation to the station scale using statistical transformations - a comparison of methods. Hydrol Earth Syst Sci 16:3383-3390

Haerter J, Hagemann S, Moseley C, Piani C (2010) Climate model bias correction and the role of timescales. Hydrol Earth Syst Sci 15:1065-1079

Hagemann S, Chen C, Haerter JO, Heinke J, Gerten D, Piani C (2011) Impact of a statistical bias correction on the projected hydrological changes obtained from three GCMs and two hydrology models. J Hydrometeorol 12:556-578

Han Z, Gao XJ, Shi Y, Wu J, Wang ML, Giorgi F (2015) Development of Chinese high resolution land cover for the RegCM4/
CLM and its impact on regional climate simulation. J Glaciol Geocryol 37:857-866 (in Chinese)

Han ZY, Tong Y, Gao XJ (2018) Correction based on quantile mapping for temperature simulated by the RegCM4. Clim Change Res 14(4):331-340 (in Chinese)

Hazeleger W, Severijns C, Semmler T et al (2010) EC-earth: a seamless earth-system prediction approach in action. Bull Am Meteorolog Soc 91:1357-1363

Hempel S, Frieler K, Warszawski L, Schewe J, Piontek F (2013) A trend-preserving bias correction-the ISI-MIP approach. Earth Syst Dyn 4:219-236

Huang J, Zhai J, Jiang T et al (2018) Analysis of future drought characteristics in China using the regional climate model CCLM. Clim Dyn 50(1-2):507-525

IPCC (2013) Climate Change 2013: the physical science basis. contribution of working group I to the fifth assessment report of the intergovernmental panel on climate change. In: Stocker TF, Qin D, Plattner GK, Tignor M, Allen SK, Boschung J, Nauels A, Xia Y, Bex V, Midgley PM (eds) Cambridge University Press, Cambridge, United Kingdom and New York, NY, USA, pp. 1535

Iversen T, Bentsen M, Bethke I et al (2013) The Norwegian earth system model, NorESM1-M-part 2: climate response and scenario projections. Geosci Model Dev 6(2):389-415

Jiang DB, Tian ZP, Lang XM (2016) Reliability of climate models for China through the IPCC third to fifth assessment reports. Int J Climatol 36:1114-1133

Jungclaus JH, Fischer H, Haak H et al (2013) Characteristics of the ocean simulations in MPIOM, the ocean componentof the MPIearth system model. J Adv Model Earth Syst 5(2):422-446

Li H, Sheffield J, Wood EF (2010) Bias correction of monthly precipitation and temperature fields from intergovernmental panel on climate change AR4 models using equidistant quantile matching. J Geophys Res 115(D10)

Liu X, Tang Q, Voisin N et al (2016) Projected impacts of climate change on hydropower potential in China. Hydrology and Earth System Sciences (Online) 20 (PNNL-SA-111934)

Maraun D (2013) Bias correction, quantile mapping, and downscaling: revisiting the inflation issue. J Clim 26:2137-2143

Mehrotra R, Sharma A (2016) A multivariate quantile-matching bias correction approach with auto- and cross-dependence across multiple time scales: implications for downscaling. J Clim 29:3519-3539

Moss RH, Edmonds JA, Hibbard KA et al (2010) The next generation of scenarios for climate change research and assessment. Nature 463(7282):747-756

MWRC (The Ministry of Water Resources of China) (1981) Preliminary assessments of water resources in China. The Ministry of Water Resources of China, Beijing (in Chinese)

Ngai ST, Tangang F, Juneng L (2017) Bias correction of global and regional simulated daily precipitation and surface mean temperature over Southeast Asia using quantile mapping method. Global Planet Change 149:79-90

Olsson J, Berggren K, Olofsson M, Viklander M (2009) Applying climate model precipitation scenarios for urban hydrological assessment: a case study in Kalmar City. Sweden Atmos Res 92(3):364-375

Piani C, Haerter JO, Coppola E (2009) Statistical bias correction for daily precipitation in regional climate models over Europe. Theoret Appl Climatol 99(1-2):187-192

Piani C, Weedon GP, Best M, Gomes SM, Viterbo P, Hagemann S, Haerter JO (2010) Statistical bias correction of global simulated daily precipitation and temperature for the application of hydrological models. J Hydrol 395(3-4):199-215

Pierce DW, Cayan DR, Maurer EP, Abatzoglou JT, Hegewisch KC (2015) Improved bias correction techniques for hydrological simulations of climate change. J Hydrometeorol 16:2421-2442 
Rotstayn LD, Collier MA, Dix MR et al (2010) Improved simulation of Australian climate and ENSO-related rainfall variability in a global climate model with an interactive aerosol treatment. Int J Climatol 30:1067-1088

Stevens B, Giorgetta M, Esch M et al (2012) The atmospheric component of the MPI-M earth system model: ECHAM6. J Adv Model Earth Syst 5:146-172

Su B, Huang J, Zeng X et al (2017) Impacts of climate change on streamflow in the upper Yangtze River basin. Clim Change 141(3):533-546

Taylor KE, Stouffer RJ, Meehl FA (2012) An overview of CMIP5 and the experiment design. Bull Amer Meteor Soc 93(4):485-498

Teutschbein C, Seibert J (2012) Bias correction of regional climate model simulations for hydrological climate-change impact studies: review and evaluation of different methods. J Hydrol 456-457:12-29

Tong Y, Gao XJ, Han ZY, Xu Y (2017) Bias correction of daily precipitation simulated by RegCM4 model over China. Chinese J Atmos Sci 41(6):1156-1166 (in Chinese)

Willems P, Vrac M (2011) Statistical precipitation downscaling for small-scale hydrological impact investigations of climate change. J Hydrol 402(3-4):193-205

Wood AW (2002) Long-range experimental hydrologic forecasting for the eastern United States. J Geophys Res 107(D20)

Wood AW, Leung LR, Sridhar V, Lettenmaier DP (2004) Hydrologic implications of dynamical and statistical approaches to downscaling climate model outputs. Clim Change 62(1):189-216

Wu J, Gao XJ (2013) A gridded daily observation dataset over China region and comparison with the other datasets. Chinese J Geophys-Chinese Edn 56:1102-1111 (in Chinese)

Wu J, Gao XJ (2020) Present day bias and future change signal of temperature over China in a series of multi-GCM driven RCM simulations. Clim Dyn 54(1):1113-1130
Xu Y, Gao XJ, Shen Y, Xu CH, Shi Y, Giorgi F (2009) A daily temperature dataset over China and its application in validating a RCM simulation. Adv Atmos Sci 26:763-772

Yang W, Andréasson J, Phil Graham L, Olsson J, Rosberg J, Wetterhall F (2010) Distribution-based scaling to improve usability of regional climate model projections for hydrological climate change impacts studies. Hydrol Res 41(3-4):211-229

Yang X, Wood EF, Sheffield J, Ren L, Zhang M, Wang Y (2018) Bias correction of historical and future simulations of precipitation and temperature for china from CMIP5 models. J Hydrometeorol 19(3):609-623

Yu ET, Wang HJ, Sun J (2015) A quick report on a dynamical downscaling simulation over China using the nested model. Atmos Oceanic Sci Lett 3(6):325-329

Zhai P, Zhang X, Wan H, Pan X (2005) Trends in total precipitation and frequency of daily precipitation extremes over China. J Clim 18(7):1096-1108

Zou LW, Zhou TJ (2013) Near future (2016-40) summer precipitation changes over China as projected by a regional climate model (RCM) under the RCP8.5 emissions scenario: Comparison between RCM downscaling and the driving GCM. Adv Atmos Sci 30(3):806-818

Zwiers FW, von Storch H (1995) Taking serial correlation into account in tests of the mean. J Clim 8:336-351

Publisher's Note Springer Nature remains neutral with regard to jurisdictional claims in published maps and institutional affiliations. 